\title{
Why Abandon the Paradise? Stations' Incentives to Reduce Gasoline Prices at First
}

\author{
Thomas Wein $^{1}$ iD
}

Received: 29 October 2020 / Revised: 22 February 2021 / Accepted: 30 March 2021 /

Published online: 27 April 2021

(C) The Author(s) 2021

\begin{abstract}
The German petrol station market is characterized by strong intraday price cycles, which probably correspond to the well-known Edgeworth cycles. The prices go up strongly in the late evening or in the middle of the night, fall relatively heavily in the early morning, and then go up and down several times in the course of the day. Locally, the analysis is limited to the 26 petrol stations that plausibly form a common market in the Lueneburg region. This paper picks out the specific sequence in which, after generally rising prices during the day, a single supplier is the first to reverse the price trend and lower its price. For this purpose, current price reports are used to define the price reduction event down to the second, and to show only the valid prices of competitors prior to the event. All German petrol stations have to report price changes to the Bundeskartellamt's Market Transparency Department. Tankerkoenig then publishes the full reports. This results in one panel observation for each price reduction event. Out of nearly 300,000 price observations, just over 10,000 panel observations result. Fixedeffect logit estimates are used to test whether the theoretically and economically significant price differences of the Edgeworth cycles explain the behavior of the price cutters, or whether market structure factors, such as brand affiliation/independence of the petrol station, service offerings, or location characteristics predict price-cutting behavior. The novel recording of the price dynamics in the petrol station market by using the accurate petrol station price data to the second indicates promising research of extensive price data and avoids the enormous loss of information in the previously common calculation of average prices at certain times.
\end{abstract}

Keywords Edgeworth cycles · Gasoline prices · Dynamic pricing

JEL Classification L13 $\cdot$ L41 $\cdot$ K21

Thomas Wein

wein@leuphana.de

1 Institute of Economics, Competition and Regulation Institute, Leuphana University of Lüneburg, Universitätsallee 1, 21335 Lüneburg, Germany 


\section{Introduction}

The price development at German filling stations is characterized by a high degree of price fluctuations. There are strong ups and downs of prices within 1 day. For example, the development of prices in Lueneburg can be traced using data from the Bundeskartellamt's Market Transparency Office. Figure 1 shows the price reports for premium gas (E5) from four selected petrol stations active in the Lueneburg town area as they were issued on 31 March 2019. The numbers represent the prices set by service stations 1, 4, 5, and 6 on that day, based on the price announcements made by the respective service stations to the Market Transparency Office (Appendix Table 19). In the figure, it is easy to see that, especially in the period between 6 a.m. and 6 p.m., prices are repeatedly raised, only to respond again with price concessions within a short time thereafter. The question remains as to why suppliers who have worked their way up to a higher price level are prepared to leave the high level. In particular, if the development repeats itself within a day and over the days, why don't suppliers learn from it and stay at high prices? Why do they voluntarily give up the price paradise?

The theoretical background for price cycles is fundamentally based on the work of Maskin and Tirole (1988). Two suppliers competing exclusively on price set their prices alternately. Only the price of the current period is relevant (Markov-strategies). If prices are set for a certain period in line with marginal costs, a war of attrition develops. One company hopes that the other loses his nerve, relents, and is the first to raise prices again. After one company increases the price (jump), the other follows with his price increase, but remains slightly below the first company's price. All the demand goes to the cheaper supplier. The too expensive supplier reacts by slightly undercutting its competitors. The now too expensive supplier also responds with price undercutting. At the end of the mutual undercutting phase, both suppliers have returned to their

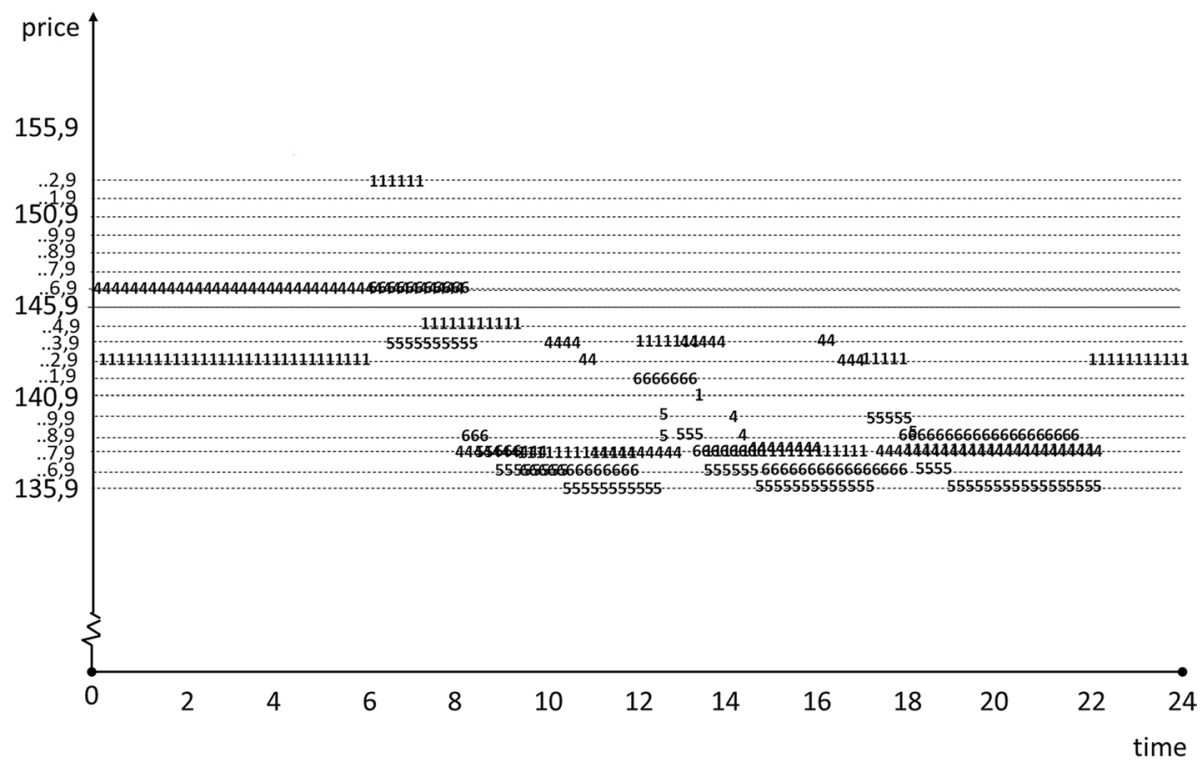

Fig. 1 Prices in Lueneburg—4 stations, 03/31/2019, Premium Gas E5. 1, Shell, Universitaetsalle; 4, Aral, Dahlenburger Landstraße; 5, LTG, Dahlenburger Landstraße; 6, Esso, Bleckeder Landstraße 
marginal costs. Then, a war of attrition, jump, and undercutting will start anew again. Noel (2008) extended this approach to three companies fighting price wars with each other. Once again, there are attrition wars, price jumps, and mutual undercutting. There are new possibilities that the subsequent price increases will be delayed (delayed starts) or even cancelled due to a lack of imitators (false starts). Stochastic price movements of input prices can influence the manifestations of cycles.

Edgeworth cycles have been empirically proven in many industrialized countries; especially the most recent work on the individual countries is presented below. Australia has recently demonstrated cycles, although, in one federal state, the rule is that petrol station prices must be kept constant for $24 \mathrm{~h}$ (Byrne and De Roos 2019; De Roos and Katayama 2013; Wang 2009a, b; Wills-Johnson and Bloch 2010). At Canadian petrol stations, there are many confirmatory indications found by evaluating long-term data at the local level (groundbreaking Noel 2007a, b; Atkinson 2009; Atkinson et al. 2014; Byrne et al. 2015). In Germany, data from the Market Transparency Office have been used in recent years to find corresponding cycles based on daily average price data at defined hours (Eibelshäuser and Wilhelm 2017; Haucap et al. 2017a; Siekmann 2017). In two Scandinavian countries, Norway and Sweden, the results for local petrol markets also point to the existence of Edgeworth cycles (Foros and Steen 2013; Nguyen and Steen 2018). The USA has the longest tradition of empirical testing for the existence of Edgeworth cycles, with confirming results available from the past decade (Doyle et al. 2010; Lewis 2012; Lewis and Noel 2011; Zimmerman et al. 2013). The well-confirmed Edgeworth cycles explain price reductions as reactions to price undercutting by one or two competitors, but they cannot explain why petrol stations reduce prices when their competitors charge almost the same prices.

It has been known for some time that powerful petrol stations are raising prices more and are unwilling to lower prices later (Borenstein and Shepard 2002; Deltas 2008). Sharply rising petrol prices can especially be observed when crude oil prices or wholesale prices go up; however, declining purchase prices are only slowly passed on to end customers. Prices rise like a rocket but fall like a feather. This "rocket-feather-relationship" was first documented by Bacon (1991), and later confirmed by Galeotti et al. (2003), and again by Verlinda (2008). Bremmer and Kesselring (2016) have recently added to this by checking whether falling cost prices during the global economic crisis in the thirties of the last century led to a contrary trend (known as "balloons and rocks"). Price cuts are thus a delayed response to falling input prices. Since input price fluctuations play a very small role in the intraday cycles under consideration, this explanatory approach is unlikely to be relevant for this paper.

One would tend to expect that rising search costs among petrol consumers would make it more difficult to compare prices at petrol stations and that stations could charge excessive prices. The easier prices can be compared, the more stable the prices will remain. Thus, there will be fewer price reductions (Chandra and Tappata 2011). Byrne and De Roos (2017) show that in times of increasing price differentials, information media with price information from petrol stations are used more frequently in corresponding websites. Haucap et al. (2017a, b) interpret the developments in German petrol price cycles as an indication of easier search activities by German final customers through information apps that provide current price data on the basis of the Market Transparency Unit (MTU). In summary, simplified search activities would increase price volatility and thus make price reductions more likely. Since search activities will hardly change within 1 day, this approach cannot be tested in this paper. 
Recently, Byrne and De Roos (2019) turned its attention to the question of how the uniform behavior of petrol station owners arises. It is therefore not the question of whether the petrol price development follows due to tacit collusion or Edgeworth cycles, but how novel price cycles are initiated. For this, they use price data from more than 600 petrol stations over a 14-year period. Due to the West Australian price rule that applies throughout this period, all petrol stations must announce the daily petrol prices on the previous day and are bound to this price for $24 \mathrm{~h}$. Due to the unusually long data set, more than 1.5 million price data are available. Supply shocks — such as natural disasters, or market entry in the petrol station market-also occurred during this time. As a result, the authors can describe relatively precisely how a change from one cycle form to another occurred. Neukirch and Wein (2019) also use local data from medium-sized cities and large German metropolises to classify brand-specific price markups in the German Edgeworth cycles, which are run several times a day using the Lerner index. The entirety of their cycles is not the object of investigation in either approach. Instead, the dynamics within the cycle (Neukirch and Wein 2019) or between the cycles (Byrne and De Roos 2019) are the focus.

Applying general microeconomic considerations, a petrol station is even more likely to reduce its price if the revenue gain from falling prices outweighs the revenue losses caused by the price reductions. Falling prices could therefore be associated with the hope of attracting additional demand. Since many petrol stations offer additional services such as shops, ATMs, toilets, car washes, bistros, baking stations, or vacuum cleaners, they have a great interest in encouraging as many customers as possible to refuel at their petrol station. Lowering the price could be a suitable measure. The longer a petrol station is open, the more likely it will sell more products, and prices will lower. Petrol stations that are further away from motorway entrances, do not offer services on main roads (federal roads), or are located along typical commuter routes with price-sensitive end customers, are more likely to reduce prices than others.

Since many petrol stations sell fuel in the name and on the account of their major, they receive a fixed fee per liter of fuel. This means that there is no loss of turnover due to price reductions. These petrol stations are all the more interested in turnover from services, which is promoted by price reductions rather than by adhering to high prices. The trend to lure customers to petrol stations by lowering prices is intensifying. Since the large majors often have card customers whose bills are paid by third parties such as their employers, customers are less willing to look for lower prices than customers at independent petrol stations. Increasing volume through price lowering is likely to be less relevant for selfservice stations or for petrol stations with associated car repair shops: the former because fixed personnel costs have to be distributed less, and the latter because the petrol station is perhaps only a source of additional profits. Petrol stations that are within sight of each other react immediately to price reductions of the other. Petrol station-specific factors such as location, service, or brand can also influence their willingness to reduce prices.

As in many other countries, excessively high gasoline prices are repeatedly the subject of political debate, as was the case in Germany at the beginning of the 2010s. As early as the end of the 2000s, the Federal Cartel Office had conducted detailed surveys of gasoline prices in four metropolitan regions and found indications of at least parallel behavior; for example, there were different prices according to weekdays or at the start of vacations. In the early 2010s, there were even calls for government intervention in the gasoline price mechanism, such as a gasoline price brake, due to generally high gasoline prices. Politically, it was then decided to set up a Market Transparency Unit for fuels, to which all gas stations have had to report their price changes within 5 min since the end of 2013. The transparency unit in turn passes these on to consumer information services, via whose 
websites, apps, or navigation devices consumers can find out about low-price suppliers. Not only consumers but also suppliers are more likely to be able to find out about relevant prices, making parallel behavior easier (Haucap et al. 2017a, b and Dewenter et al. 2017).

This paper examines why a service station is the first to lower prices after a period of rising prices, within the intraday German Edgeworth cycles. Edgeworth cycle theory would require price undercutting by a competitor. Petrol stations with market power would be less forced to lower prices than powerless ones. More interest in selling additional services, the location of the petrol station, and existing brand loyalty may also be reasons to be the first to give up the high-price paradise. The second chapter describes the service station market in Lüneburg and compares it with the national market. The third chapter shows which price data are available from the MTU and how a panel data set can be created from them, based on the (price) data of the 26 gas stations recorded for each price reduction round. Descriptive statistics are provided within Section 4. Section 5 describes the estimated results of multivariate fixed effect logit estimates of why a single service station lowers their price and the others do not. Robustness tests are presented in Section 6. Summarized results and conclusions can be found in the seventh section.

\section{The Gasoline Market in Lueneburg}

The incentives of a service station to be the first to lower its price must be measured in the context of an appropriate market definition. In this paper, the 15 service stations located in the city of Lüneburg (around 75,000 inhabitants) and the eleven service stations in neighboring municipalities are combined to form a local market (Fig. 2). Two petrol stations (Aral Brietlingen, No. 21, and Raiffeisen Barendorf, No. 23) ceased operations in the course of 2019. The city of Lüneburg and neighboring villages such as Adendorf (10,800 inhabitants) or Reppenstedt with 7400 inhabitants certainly represent the major part of the demand for gasoline. The next bigger cities like Uelzen with about 41,000 inhabitants or Hamburg with $1.8 \mathrm{~m}$ are far away (41 and $57 \mathrm{~km}$ respectively). The freeway ends in Lüneburg and two federal highways cross the Lüneburg city area. In terms of traffic, therefore, relatively little through traffic is to be expected, which has little influence on the demand for fuels. In this respect, a locally dominated market is more likely.

With the aid of Google Maps, the shortest route between the individual filling stations was determined manually, whereby the mean value of both directions was taken as a basis (Table 2, and the allocation of each station to its nearest, second nearest and third nearest competitor according to Appendix Table 20). Although there are distances of up to $20 \mathrm{~km}$ between individual gas stations, this is mainly true for suppliers from opposite villages. The vast majority of gas stations are less than $10 \mathrm{~km}$ apart (Table 1).

Other station-specific characteristics are recorded for the individual filling stations, however: for example, other products offered by the filling station, opening times, spatial location, average consumer satisfaction (values between 1 and 5), as well as the type of road traffic connection. We evaluated data from the app-based information services Clever Tanken and Tankerkönig by using Google Maps. Information from individual stations' webpages are included as well as the author's local knowledge. Tables 21 and 22 in the Appendix provide information on the characteristics of each service station. 


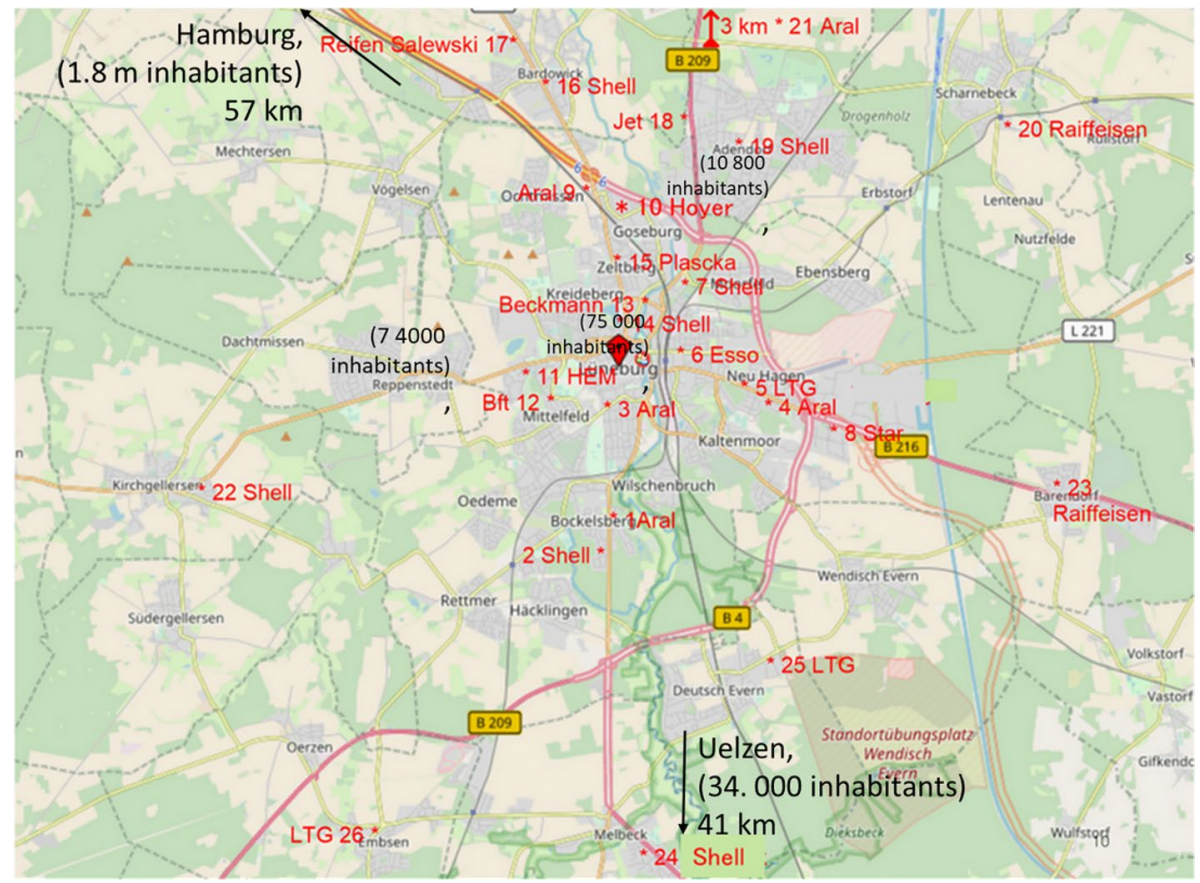

Fig. 2 Filling stations_-region of Lueneburg versus Germany

A total of 26 petrol stations are included in the data set for the Lueneburg region, of which 15 are in the city area and eleven in neighboring municipalities (Fig. 2). Two petrol stations (Aral Brietlingen, No. 21, and Raiffeisen Barendorf, No. 23) ceased operations in the course of 2019.

Table 1 Distances between filling stations

\begin{tabular}{|c|c|c|c|c|c|c|c|c|c|c|c|c|c|c|c|c|c|c|c|c|c|c|c|c|c|c|c|c|c|}
\hline & & & id & 1 & 2 & 3 & 4 & \multirow[t]{2}{*}{5} & \multirow[t]{2}{*}{6} & & \multirow[t]{2}{*}{$8 \mid$} & & \multirow{2}{*}{\begin{tabular}{|l|l}
10 \\
\end{tabular}} & \multirow{2}{*}{\begin{tabular}{l|l}
11 & 1 \\
\end{tabular}} & \multirow{2}{*}{\begin{tabular}{l|l}
12 & 1 \\
\end{tabular}} & \multirow{2}{*}{\multicolumn{2}{|c|}{\begin{tabular}{|l|l|}
3 & 14 \\
\end{tabular}}} & \multirow{2}{*}{\begin{tabular}{|l|}
15 \\
\end{tabular}} & \multirow{2}{*}{\begin{tabular}{|l|l}
16 \\
\end{tabular}} & \multirow{2}{*}{\begin{tabular}{|l|l}
17 \\
\end{tabular}} & \multirow[t]{2}{*}{\begin{tabular}{|l|l|}
18 & $1 \mathrm{~s}$ \\
\end{tabular}} & \multirow{2}{*}{\multicolumn{2}{|c|}{20}} & 21 & 22 & 23 & 24 & 25 & 26 \\
\hline id & and & Street & Place & \multirow{2}{*}{\multicolumn{2}{|c|}{\begin{tabular}{|l|l|}
- & 0.28 \\
\end{tabular}}} & \multirow[b]{2}{*}{$282.75 \mid$} & \multirow[b]{2}{*}{$4.80 \mid 8$} & & & & & & & & & & & & & & & & & & & & & & \\
\hline 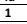 & (n) & \multirow{2}{*}{ Universitaetsallee } & \multirow{15}{*}{ Lueneburg } & & & & & 8.00 & $3.80 \mid 4$ & $4.90 \mid 6$ & $6.90 \mid 6$ & $5.50 \mid 6$ & $\begin{array}{l}6.70{ }_{3}^{3} \\
\end{array}$ & $3.90 \mid 3$ & \begin{tabular}{ll|l|l|}
$\left.3.50\right|^{2}$ \\
\end{tabular} & \begin{tabular}{ll|l}
2.90 & 4. \\
\end{tabular} & \begin{tabular}{l|l|}
4.10 & 1. \\
\end{tabular} & \begin{tabular}{|l|l|}
1.10 & 8. \\
\end{tabular} & \begin{tabular}{l|l|l}
8.90 & 8 \\
\end{tabular} & \begin{tabular}{l|l|}
8.90 & \\
\end{tabular} & \begin{tabular}{l|l}
7.86 \\
\end{tabular} & 301 & $11.60 \mid 1$ & 12.50 & 10.50 & 10.0 & 5.30 & 4.80 & 8.50 \\
\hline 2 & \multirow{3}{*}{ ARAL } & & & & - & 2.10 & 4.60 & 3.90 & 3.70 & 3.906 & 6.35 5 & 5.706 & \begin{tabular}{ll|l}
6.40 & 3 \\
\end{tabular} & \begin{tabular}{ll|l}
3.90 & 3 \\
\end{tabular} & 3.204 & \begin{tabular}{l|l}
4.20 & 4. \\
\end{tabular} & \begin{tabular}{l|l|}
4.70 & 4. \\
\end{tabular} & \begin{tabular}{l|l}
4.95 & 8. \\
\end{tabular} & \begin{tabular}{l|l}
8.10 & 8 \\
\end{tabular} & 8.607 & 7.606 & 6.701 & $11.40 \mid 1$ & 12.30 & 10.00 & \begin{tabular}{|l|}
9.80 \\
\end{tabular} & 5.50 & 4.80 & 9.00 \\
\hline 3 & & Soltauer Strasse & & \begin{tabular}{|l}
- \\
\end{tabular} & - & - & 3.70 & 3.05 & 2.85 & 3.905 & 5.454 & 4.856 & 6.451 & 1.801 & 1.003 & \begin{tabular}{l|l}
3.25 & 3. \\
\end{tabular} & \begin{tabular}{l|l}
3.20 & 4 \\
\end{tabular} & 4.057 & $\begin{array}{l}7.307 \\
\end{array}$ & \begin{tabular}{l|l|l}
7.606 \\
\end{tabular} & 6.805 & 5.901 & 10.601 & 11.40 & 7.80 & \begin{tabular}{|l|}
9.00 \\
\end{tabular} & \begin{tabular}{|l|l|}
7.90 \\
\end{tabular} & 7.30 & 8.40 \\
\hline 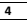 & & hle & & 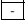 & - & - & - & 0.65 & 1.80 & 3.35 & 1.705 & 5.505 & \begin{tabular}{l|l}
5.805 \\
\end{tabular} & \begin{tabular}{l|l}
5.15 & 3 \\
\end{tabular} & 3.603 & \begin{tabular}{ll|l}
3.60 & 3. \\
\end{tabular} & \begin{tabular}{l|l}
3.30 & 4. \\
\end{tabular} & $\begin{array}{l}4.407 .7 . \\
\end{array}$ & \begin{tabular}{l|l}
7.50 & 8 \\
\end{tabular} & 8.906 & $\begin{array}{l}6.405 \\
\end{array}$ & \begin{tabular}{l|l}
5.45 \\
\end{tabular} & 7.651 & 10.90 & 11.40 & 5.20 & 10.30 & 5.65 & 13.30 \\
\hline 5 & LTG & Landstr & & - & - & - & - & $-x_{-1}$ & 1.25 & 3.402 & 2.404 & 4.805 & 5.204 & 4.303 & 3.502 & 2.902 & 2.603. & \begin{tabular}{l|l|}
3.70 & 6. \\
\end{tabular} & 6.907 & \begin{tabular}{l|l}
7.40 \\
\end{tabular} & 6.355 & 5.50 & \begin{tabular}{l|l}
8.35 & 1 \\
\end{tabular} & 11.00 & 10.60 & \begin{tabular}{|l|}
5.80 \\
\end{tabular} & 10.90 & \begin{tabular}{|l|}
6.35 \\
\end{tabular} & 14.00 \\
\hline 6 & Esso & $\begin{array}{l}\text { Bl } \\
\mathrm{La}\end{array}$ & & - & - & - & - & - & - & 2.853 & 3.654 & 4.404 & \begin{tabular}{l|l}
4.70 & 5
\end{tabular} & $\left.5.60\right|^{3}$ & 3.702 & $2.40 \mid 2$. & 2.603. & 3.205 & $\begin{array}{l}5.90 \\
7\end{array}$ & 7.205 & 5.404 & 4.50 & 8.051 & 10.00 & 9.40 & 7.30 & 9.00 & 7.45 & 10.90 \\
\hline 7 & Shell & $\begin{array}{l}\text { Erbstorfer } \\
\text { Landstr. }\end{array}$ & & - & - & - & - & - & - & - & 4.75 3 & 3.503 & $3.90 \mid 4$. & \begin{tabular}{l|l}
4.00 & 4.
\end{tabular} & $\begin{array}{l}4.05 \mid 1 \\
|r| r \mid\end{array}$ & \begin{tabular}{l|l}
1.35 & 2. \\
\end{tabular} & \begin{tabular}{l|l}
2.00 & 2. \\
\end{tabular} & $2.40 \mid 5$. & \begin{tabular}{l|l}
5.10 & 6
\end{tabular} & 6.103 & 3.15 & 2.30 & 6.70 & 7.85 & $|10.00|$ & $8.20 \mid$ & 12.90 & 8.25 & 12.10 \\
\hline 8 & STAR & den Bloe & & - & - & - & - & - & - & - & - & 7.358 & \begin{tabular}{l|l}
8.05 & 6 \\
\end{tabular} & \begin{tabular}{l|l}
6.45 & 6 \\
\end{tabular} & \begin{tabular}{l|l}
6.35 & 5 \\
\end{tabular} & \begin{tabular}{l|l}
5.80 & 5.
\end{tabular} & \begin{tabular}{l|l}
5.50 & 5.
\end{tabular} & \begin{tabular}{l|l}
5.709. \\
\end{tabular} & \begin{tabular}{l|l}
9.10 & 16 \\
\end{tabular} & 16.90 & 7.506 & 6.60 & 9.101 & 12.201 & 13.20 & \begin{tabular}{|l|}
4.50 \\
\end{tabular} & 10.20 & 5.65 & 13.30 \\
\hline 9 & ARAL & $\begin{array}{l}\text { Hamburger } \\
\text { Strasse }\end{array}$ & & . & - & - & - & - & - & - & - & - & \begin{tabular}{l|l}
0.60 & 4 \\
\end{tabular} & \begin{tabular}{l|l}
4.60 & 3. \\
\end{tabular} & 3.052 & $2.35 \mid 2$. & \begin{tabular}{l|l}
2.40 & 1. \\
\end{tabular} & 1.10 & \begin{tabular}{l|l}
2.40 & 2 \\
\end{tabular} & 2.703 & 3.403 & 3.20 & 8.20 & 9.50 & 10.8 & 1.2 & 11.7 & 11.20 & 13.6 \\
\hline 10 & Hoyer & Bessemerstr. & & - & - & - & - & \begin{tabular}{|l|}
- \\
\end{tabular} & - & - & - & - & $\begin{array}{l}-5 \\
\end{array}$ & $\begin{array}{ll}5.003 \\
\end{array}$ & 3.902 & \begin{tabular}{l|l}
2.602. \\
.
\end{tabular} & \begin{tabular}{l|l}
2.60 & 1.
\end{tabular} & \begin{tabular}{l|l}
1.502. \\
.
\end{tabular} & \begin{tabular}{l|l}
2.60 & 3 \\
\end{tabular} & 3.103 & 3.203 & 3.201 & 10.40 & 9.60 & 11.00 & 11.50 & 11.901 & \begin{tabular}{|l|}
11.30 \\
\end{tabular} & 13.80 \\
\hline 11 & HEM & $\begin{array}{l}\text { Vo } \\
\text { To }\end{array}$ & & - & - & - & - & - & - & - & - & - & - & -4 & 4.603 & 3.053. & $3.20 \mid 3$. & \begin{tabular}{l|l}
3.50 & 6. \\
\end{tabular} & 6.607 & 7.806 & $6.90 \mid 6$ & $\begin{array}{ll}6.00 & 1\end{array}$ & $10.60 \mid 1$ & 11.60 & 6.10 & $10.80 \mid$ & 9.40 & 9.00 & 9.90 \\
\hline 12 & Bft & Am Grasweg & & - & - & - & - & - & - & - & - & - & - & - & - & \begin{tabular}{l|l}
5.102. \\
\end{tabular} & \begin{tabular}{l|l}
2.55 & 3.
\end{tabular} & \begin{tabular}{l|l}
3.55 & 6. \\
\end{tabular} & \begin{tabular}{l|l}
6.907 \\
\end{tabular} & 7.307 & 7.006 & 6.101 & 10.801 & 11.60 & \begin{tabular}{|l|}
6.80 \\
\end{tabular} & 10.10 & \begin{tabular}{|l|}
8.70 \\
\end{tabular} & 8.30 & 9.20 \\
\hline 13 & Beckmann/Lindemann & - & & - & $\therefore$ & - & - & - & - & - & - & - & - & - & - & 0 & \begin{tabular}{l|l}
0.75 & 1. \\
\end{tabular} & 1.204 & \begin{tabular}{l|l}
4.30 & 4 \\
\end{tabular} & 4.904 & 4.30 & 3.40 & 8.00 & 9.00 & \begin{tabular}{|l|}
9.05 \\
\end{tabular} & 9.20 & \begin{tabular}{|l|}
9.70 \\
\end{tabular} & \begin{tabular}{|l|}
9.10 \\
\end{tabular} & 11.60 \\
\hline 14 & Shell & $\begin{array}{l}\mathrm{Vo} \\
\mathrm{Ba}\end{array}$ & & . & - & - & - & - & - & - & - & - & - & - & - & - & -2 & \begin{tabular}{l|l}
2.40 & 4. \\
\end{tabular} & \begin{tabular}{l|l}
4.60 & 4 \\
\end{tabular} & 4.804 & \begin{tabular}{l|l}
4.90 & 4 \\
\end{tabular} & 4.05 & 8.70 & 9.55 & 8.40 & 8.80 & 9.40 & 8.90 & 11.30 \\
\hline 15 & Freie Tankstelle & bur & & - & - & - & - & - & - & - & - & - & - & - & - & - & - & -3. & \begin{tabular}{l|l} 
& \\
3.20 & 3 \\
\end{tabular} & 3.705 & 5.304 & 4.50 & 9.10 & 10.00 & 9.50 & 9.80 & 10.40 & \begin{tabular}{|l|}
9.80 \\
\end{tabular} & 12.30 \\
\hline 16 & & & & - & - & - & - & - & - & - & - & - & - & - & - & - & - & - & 0 & 0.804 & 4.606 & 6.30 & 9.40 & 7.30 & 11.00 & 16.20 & 14.10 & 13.90 & 16.00 \\
\hline 17 & $\begin{array}{l}\text { Freie Tank } \\
\text { Salewski }\end{array}$ & Istr. & dowick & - & - & - & - & - & . & - & - & - & - & - & - & - & - & - & - & - & 4.80 & 6.50 & 9.60 & 7.50 & 11. & 16.4 & 14. & 13.70 & 90 \\
\hline 18 & JET & $\begin{array}{l}\text { Artlenburger } \\
\text { Landstr. }\end{array}$ & tendorf & - & - & - & - & - & - & - & & - & - & - & - & - & - & - & - & - & & 1.80 & 6.90 & 4.80 & $13.0 \mathrm{c}$ & 11 & 13.16 & 11.50 & 15.00 \\
\hline 19 & & & & & - & - & - & & - & - & & & - & - & - & - & - & - & - & - & & & 6.40 & 6.50 & 12.10 & 10.90 & 15.10 & 10.60 & \\
\hline 20 & $R_{c}$ & & & - & - & - & - & - & - & - & - & - & - & - & - & - & - & - & - & - & - & - & & 7.60 & 16.70 & 8.50 & 16.90 & 12.90 & 18.80 \\
\hline 21 & ARAl & Bundesstra $B$ & & - & ( & - & - & 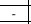 & - & ${ }_{-}$ & 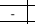 & - & 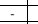 & - & - & - & - & - & - & - & 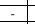 & 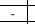 & - & - & 18.10 & 16.20 & 17.70 & 16.10 & 19.6 \\
\hline 22 & & & & & - & - & - & - & & 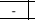 & - & - & - & - & - & - & - & - & - & - & - & - & - & - & - & 17.90 & 12.70 & 13.80 & 8.80 \\
\hline 23 & $R_{a}$ & eneburger & & & 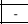 & - & - & - & - & - & & - & - & - & - & - & - & - & - & - & - & - & - & - & - & - & 14.20 & 9.60 & $\mid 17.70$ \\
\hline 24 & Shell & 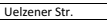 & & & & - & - & - & - & - & - & - & - & - & - & - & - & - & - & - & - & - & - & - & - & - & - & 5.00 & 4.50 \\
\hline 25 & LTG & 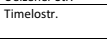 & & - & -5 & - & - & - & - & - & & - & - & - & - & - & . & - & . & . & 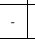 & 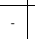 & - & - & . & - & $T_{-1}$ & - & 8.10 \\
\hline 26 & & Bahnhofstr. & \begin{tabular}{|l|} 
Embsen \\
\end{tabular} & & - & - & - & - & - & - & - & $\therefore$ & - & - & - & - & - & - & - & - & - & - & - & - & - & - & - & - & - \\
\hline
\end{tabular}

Mean value of both directions; own calculations 
Table 2 Filling stations—region of Lueneburg versus Germany

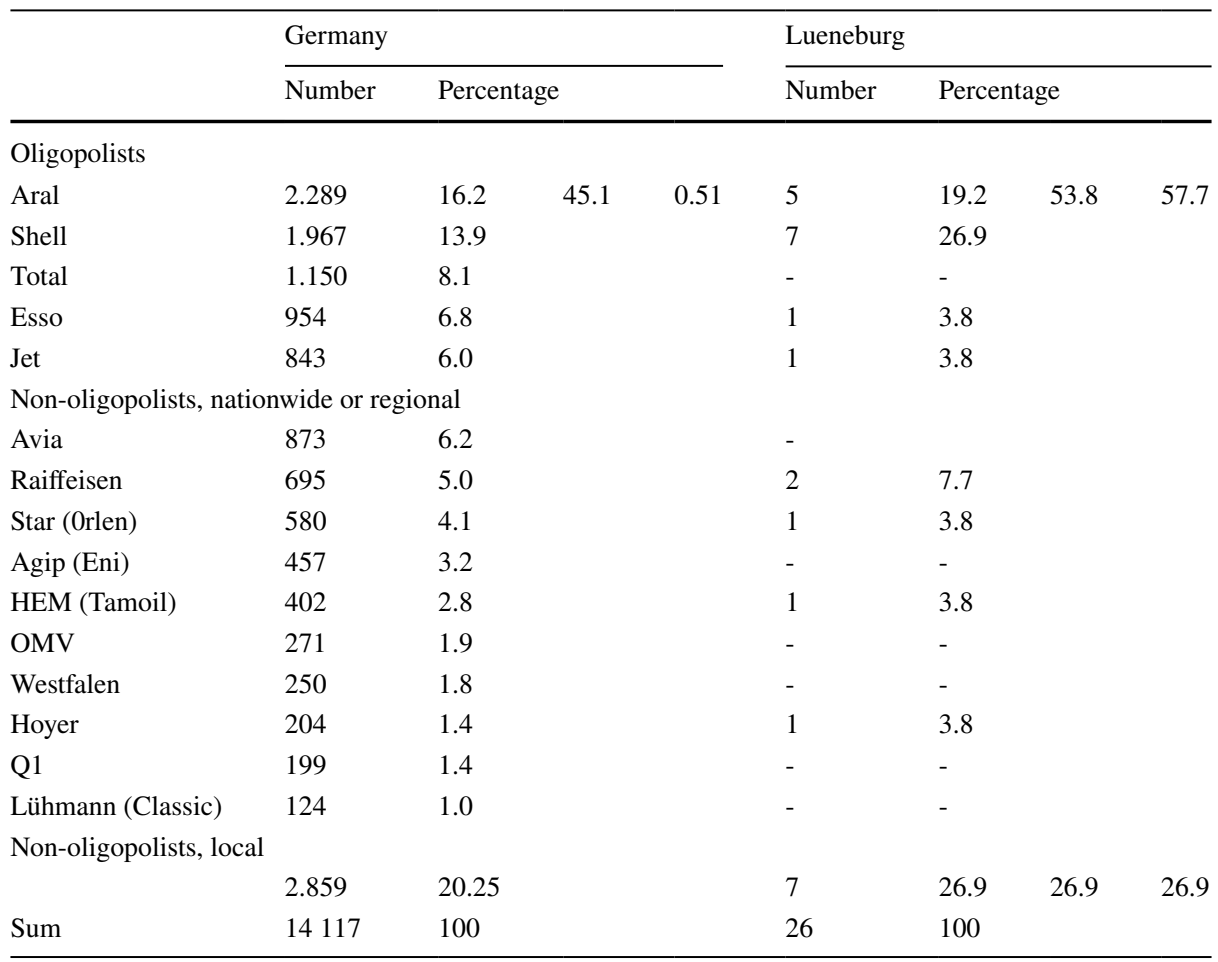

${ }^{1}$ ADAC 2020; ${ }^{2}$ Own Dataset. Own calculations

All filling stations are assigned to the brands of the five majors (nationwide, with own upstream facilities; Aral, Shell, Esso, Total, Jet), to the superregional without upstream structure acting as non-oligopolists 1 (star, AVIA, HEM, OIL!, Agip, OMV, Westfalen, NO1), or to the independent, locally active filling stations (non-oligopolists 2, NO2). If we compare the relevance of the individual brands in Lueneburg with those in Germany (excluding autobahn service stations; Table 2), it is noticeable that in percentage terms the oligopolists and the local, independent service stations are more important, at the detriment of the supraregional brands without their own upstream facilities such as their own refineries. However, the differences are not so great that a fundamentally different functioning of the (local) gasoline market is to be expected here.

Of course, it would be desirable to base the analysis of price data not only on a local market. However, a proper analysis requires the knowledge or the detailed study of the local topographical or traffic conditions. The automated distance measurement options available on the Internet are often flawed because, for example, the direct routes to and from service stations are calculated incorrectly. Only in the case of a third-partyfunded, as yet unapproved research project with the goal of a detailed case-by-case analysis can sufficient accuracy be achieved, especially if one does not have sufficient local knowledge. Furthermore, sufficient research interest alone must be assumed as to how service stations react to the price behavior of their competitors every day, every hour or minute, or even every second. 


\section{Data and Price Decreasing Panel Data Set}

Since December 2013, the legal requirements for the activities of the Market Transparency Unit (MTU) of the Federal Cartel Office have been in place. Filling stations must notify MTU of their new prices within $5 \mathrm{~min}$. The agreements with individual providers of information services via the Internet or Apps have been available for public download and kept up to date for many years on the Tankerkönig.de homepage. Unfortunately, there is no quantity data available at the filling station level. In this paper, I limit reports to the Lueneburg region with the fuel types diesel and petrol (unleaded E5 and E10), for the years 2018 and 2019.

All diesel price data provided by Tankerkönig for petrol station 1 (Shell Universitaetsallee) on the third and fourth of January 2018 are shown in Table 3. If the variable "startprice" equals 1 , this means that the last price of the previous day was leaked. A start price

Table 3 Price announcements Shell, Universitaetsallee 1, diesel, January, 3.+4., 2018

\begin{tabular}{|c|c|c|c|c|c|}
\hline & Time & Timeh & Price in ct & startprice & pdif \\
\hline \multirow[t]{15}{*}{$01 / 03 / 2028$} & 00:00:00 & 0.0 & 131.9 & 1 & 15 \\
\hline & $05: 17: 05$ & 5.3 & 128.9 & 0 & -3 \\
\hline & $06: 32: 06$ & 6.5 & 124.9 & & -4 \\
\hline & 07:02:06 & 7.0 & 123.9 & & -1 \\
\hline & 10:02:06 & 10.0 & 119.9 & & -4 \\
\hline & $12: 30: 07$ & 12.5 & 124.9 & & 5 \\
\hline & $14: 47: 06$ & 14.8 & 121.9 & & -3 \\
\hline & $15: 47: 06$ & 15.8 & 119.9 & & -2 \\
\hline & 17:00:07 & 17.0 & 122.9 & & 3 \\
\hline & 18:18:06 & 18.3 & 121.9 & & -1 \\
\hline & $19: 44: 12$ & 19.7 & 120.9 & & -1 \\
\hline & 20:08:06 & 20.1 & 118.9 & & -2 \\
\hline & $20: 45: 07$ & 20.8 & 117.9 & & -1 \\
\hline & 21:05:06 & 21.1 & 116.9 & & -1 \\
\hline & 22:00:06 & 22.0 & 131.9 & & 15 \\
\hline \multirow[t]{15}{*}{$01 / 04 / 2028$} & 00:00:00 & 0.0 & 131.9 & 1 & 15 \\
\hline & 05:18:06 & 5.3 & 128.9 & 0 & -3 \\
\hline & 06:32:06 & 6.5 & 124.9 & & -4 \\
\hline & $06: 51: 06$ & 6.9 & 123.9 & & -1 \\
\hline & 09:47:07 & 9.8 & 119.9 & & -4 \\
\hline & $12: 30: 07$ & 12.5 & 124.9 & & 5 \\
\hline & $13: 38: 07$ & 13.6 & 122.9 & & -2 \\
\hline & $14: 44: 07$ & 14.7 & 119.9 & & -3 \\
\hline & $16: 12: 06$ & 16.2 & 117.9 & & -2 \\
\hline & 17:00:07 & 17.0 & 120.9 & & 3 \\
\hline & 18:18:06 & 18.3 & 119.9 & & -1 \\
\hline & $18: 47: 06$ & 18.8 & 118.9 & & -1 \\
\hline & 18:56:06 & 18.9 & 117.9 & & -1 \\
\hline & 20:02:06 & 20.0 & 116.9 & & -1 \\
\hline & 22:00:07 & 22.0 & 131.9 & & 15 \\
\hline
\end{tabular}

Open $0 / 24$; own calculations 
variable with a value of 0 shows a daily price message: for example, the first new price at 5.17 and five seconds in the morning with a value of 128.9 Eurocents (ct), i.e., a price reduction of 3 ct compared to the previous day. All further price messages on January 3 , 2018, are then again new price messages. For January 4, 2018, the last price message of the previous day (January 3) is also fed before all new price changes of the current day are displayed. With the variables "open" and "close," the opening and closing times of the respective petrol station are displayed. Petrol station 1 is open all day. The variable "timemh" measures the time period between midnight and the announcement of the new price in machine hours. Hence, a calculable time distance is provided, in addition to the non-useable variable "time." If a petrol station had not been open all day, machine hour time would be calculated from the opening time. On January 3, there are 14 new price messages, of which three are increases (by 5, 3, and $15 \mathrm{ct}$ ) and eleven occur as reductions (between - 1 and $-4 \mathrm{ct}$ ). One day later, it looks relatively similar. There are drastic price increases in the evening, two moderate price increases $(+3$ and $+5 \mathrm{ct}$ ), and again many small reduction rounds between -1 and -4 ct.

Table 4 includes the data set that was extended to include all petrol stations in the Lueneburg region for the morning of January 3. Starting in the early hours of the morning, the petrol stations that are not continuously open only start operating. At that point, price observations should only be included in the data set of relevant price reductions when all petrol stations are open. On this day, the filling stations 25 and 26 did not open until 7 o'clock in the morning and obviously only after the usual price increases of $10 \mathrm{ct}$ on the previous day had been followed up. It comes now again to a price reduction of 21 (Aral in Brietlingen) at a value of $2 \mathrm{ct}$. This price reduction is referred to as a price reduction relevant to the investigation (event =1); however, it is perhaps atypical, since Aral Brietlingen rather participated in the early morning price reduction. Data was prepared in such a way that the most recent price message is displayed from every petrol station relevant in the market area. All other, older price reports, of course only from open petrol stations, were deleted for this price reduction round. On the same day (January 3), the next first price reduction by 21 (Aral-Brietlingen) occurs at 12:10:06 by $2 \mathrm{ct}$, after the petrol stations 2, 3, 21,4 , and 9 (all Aral) have increased their prices mostly up to $5 \mathrm{ct}$, and all at the same time shortly after 12 o'clock. The reduction of 21 is referred to as the next price reduction event. Again, for all local petrol stations, including those of the defined price decreaser, only the most recent price messages are stored in the data record. In this case, only price messages that occurred January 3 or later were kept. Since some petrol stations had not yet set new prices on New Year's Day 2018, only the comprehensive price data of January 2 can be used to place them into the data set for January 3. In this respect, my data set does not start until January 3, 2018.

Table 5 shows the first price reduction events of the first 2 days of the modified data set for diesel in the Lueneburg region. At about half past 7 in the morning, petrol station 21 (Aral, Brietlingen) lowered prices after two other petrol stations (25, 26 LTG in Deutsch Evern and Embsen) had once again sharply increased their prices. As for the first day, both price increases are more likely to be the same as the previous day's price increases. Further in the course of this paper, whether these price reductions represent a separate case category should be examined. If more than one petrol station reacts to the same price situation with a price reduction at the same second, it is recorded as a further price reduction event and thus as another price reduction round.

Table 6 shows the chronological sequence of January 3, 2018, for three price reduction events (rounds 0-2), the two already introduced at 7:30:07 and 12:10:06 at petrol station 21 and the new petrol station 4 (Aral Lueneburg, Dahlenburger Landstraße). Petrol station 
Table 4 Relevant data, January 3, 2018, Lueneburg region

\begin{tabular}{|c|c|c|c|c|c|c|c|c|c|c|c|}
\hline Time & Id & Price & startprice & pdif & Event & Time & id & Price & startprice & pdif & Event \\
\hline \multirow[t]{7}{*}{ 00:00:00 } & 14 & 122.9 & 1 & -9 & & 08:35:07 & 23 & 119.9 & 0 & -2 & \\
\hline & 18 & 125.9 & & 11 & & 08:36:06 & 20 & 119.9 & & -2 & \\
\hline & 15 & 122.9 & & 5 & & 08:53:06 & 24 & 119.9 & & -4 & \\
\hline & 20 & 121.9 & & 6 & & 10:02:06 & 1 & 119.9 & & -4 & \\
\hline & 5 & 121.9 & & 7 & & 10:13:06 & 17 & 120.9 & & -1 & \\
\hline & 23 & 121.9 & & 6 & & $10: 15: 08$ & 22 & 118.9 & & -3 & \\
\hline & 13 & 123.9 & & 7 & & $10: 32: 06$ & 12 & 117.9 & & -3 & \\
\hline 03:53:05 & 11 & 121.9 & & 8 & & 10:38:07 & 11 & 117.9 & & -3 & \\
\hline 04:05:06 & 22 & 122.9 & & 8 & & $10: 49: 10$ & 14 & 118.9 & & -2 & \\
\hline 05:17:05 & 7 & 122.9 & 0 & -9 & & 10:54:06 & 10 & 117.9 & & -1 & \\
\hline 05:21:06 & 12 & 121.9 & 1 & 7 & & 11:11:06 & 15 & 117.9 & & -4 & \\
\hline 05:25:06 & 19 & 122.9 & & 7 & & $11: 23: 06$ & 13 & 118.9 & & -1 & \\
\hline \multirow[t]{2}{*}{ 05:33:06 } & 8 & 121.9 & 0 & -4 & & 11:26:06 & 7 & 118.9 & & -2 & \\
\hline & 9 & 124.9 & & -13 & & 11:47:06 & 8 & 117.9 & & -1 & \\
\hline 06:01:06 & 21 & 124.9 & 1 & 7 & & $11: 55: 06$ & 6 & 118.9 & & -2 & \\
\hline 06:10:06 & 4 & 123.9 & 0 & -4 & & 11:56:06 & 18 & 115.9 & & -2 & \\
\hline \multirow[t]{2}{*}{$06: 26: 06$} & 17 & 121.9 & & 6 & & 11:57:06 & 5 & 117.9 & & -1 & \\
\hline & 6 & 122.9 & & -6 & & 11:59:06 & 26 & 117.9 & & -1 & \\
\hline \multirow[t]{2}{*}{$06: 31: 06$} & 3 & 123.9 & & -5 & & & 16 & 118.9 & & -1 & \\
\hline & 2 & 123.9 & & -5 & & & 25 & 117.9 & & -1 & \\
\hline 06:33:06 & 10 & 121.9 & & -2 & & $12: 05: 06$ & 19 & 116.9 & & -2 & \\
\hline 06:43:06 & 24 & 123.9 & & -1 & & 12:06:06 & 2 & 124.9 & & 5 & \\
\hline 06:44:06 & 16 & 124.9 & & -2 & & & 3 & 124.9 & & 5 & \\
\hline 07:02:06 & 1 & 123.9 & & -1 & & & 21 & 125.9 & & 5 & \\
\hline 07:03:06 & 26 & 124.9 & & 10 & & & 4 & 123.9 & & 3 & \\
\hline 07:05:06 & 25 & 124.9 & & 10 & & $12: 07: 06$ & 9 & 125.9 & & 5 & \\
\hline 07:30:07 & 21 & 122.9 & $\mathbf{0}$ & -2 & 1 & 12:10:06 & 21 & 123.9 & 0 & -2 & 1 \\
\hline
\end{tabular}

Own calculations

4 lowered the price by 1 ct to 122.9 at 12:32:04, after it had increased the price by 4 ct at 12:06:06. Their price reduction was defined as a new price reduction event, as the four petrol stations $(\# 7,16,12,1)$ had increased their prices by 3 and 5 ct respectively. All the current price reports for the petrol stations that were submitted before are still valid, of course. The crossed-out price changes (pdif) in Table 6 are irrelevant for the definition of the price reduction event, since it is only the next price reduction event after 12:10:06 that is at issue. In order to enable later estimates at the price reduction round level, a three-digit number is assigned to each day $(1 / 3 / 2018=300,1 / 4 / 2018=400, \ldots, 2 / 1 / 2018=3200, \ldots)$. If the respective lap counter is also combined with this order number, a unique designation of the respective intraday lap results. Looking back from the time of the price reduction event, the variable "duration" indicates how long the respective "pre-price" has already been set in the market area (in machine hours).

Table 7 summarizes the modified data set as it is used for further analysis, here concerning the price reduction event rounds \#300 to \#302. The variable "pricediff" indicates how the competitors of the price decreaser deviate from the new price of the price decreaser 
Table 5 First price reductions on the first 2 days of the data set

\begin{tabular}{|c|c|c|c|c|c|c|c|c|c|c|c|c|c|c|c|}
\hline Date & Time & Id & price & \begin{tabular}{|l} 
startprice \\
\end{tabular} & pdif & Event & round & date & Time & id & price & startprice & pdif & Event & round \\
\hline \multirow{27}{*}{ 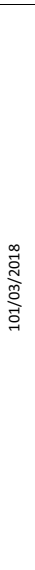 } & \multirow{7}{*}{ 00:00:00 } & 23 & 121.9 & \multirow{9}{*}{1} & 6 & & \multirow{26}{*}{0} & \multirow{27}{*}{ 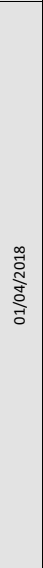 } & \multirow{6}{*}{ 00:00:00 } & 20 & 121.9 & \multirow{8}{*}{1} & 4 & & \multirow{27}{*}{0} \\
\hline & & 13 & 123.9 & & 7 & & & & & 15 & 117.9 & & -4 & & \\
\hline & & 15 & 122.9 & & 5 & & & & & 13 & 123.9 & & 5 & & \\
\hline & & 5 & 121.9 & & 7 & & & & & 5 & 121.9 & & 7 & & \\
\hline & & 14 & 122.9 & & -9 & & & & & 23 & 121.9 & & 4 & & \\
\hline & & 18 & 125.9 & & 11 & & & & & 14 & 122.9 & & -9 & & \\
\hline & & 20 & 121.9 & & 6 & & & & 03:55:06 & 11 & 121.9 & & 7 & & \\
\hline & 03:53:05 & 11 & 121.9 & & 8 & & & & 04:05:07 & 22 & 122.9 & & 8 & & \\
\hline & 04:05:06 & 22 & 122.9 & & 8 & & & & $05: 18: 06$ & 7 & 122.9 & 0 & -9 & & \\
\hline & 05:17:05 & 7 & 122.9 & 0 & -9 & & & & 05:21:06 & 12 & 121.9 & 1 & 7 & & \\
\hline & 05:21:06 & 12 & 121.9 & 1 & 7 & & & & $05: 29: 05$ & 19 & 122.9 & 1 & 7 & & \\
\hline & $05: 25: 06$ & 19 & 122.9 & 1 & 7 & & & & \multirow{2}{*}{ 05:33:05 } & 8 & 121.9 & 0 & -4 & & \\
\hline & \multirow{2}{*}{ 05:33:06 } & 8 & 121.9 & 0 & -4 & & & & & 9 & 124.9 & 0 & -14 & & \\
\hline & & 9 & 124.9 & 0 & -13 & & & & 05:42:06 & 18 & 121.9 & 0 & -4 & & \\
\hline & 06:01:06 & 21 & 124.9 & 1 & 7 & & & & 06:00:06 & 21 & 124.9 & 1 & 7 & & \\
\hline & $06: 10: 06$ & 4 & 123.9 & 0 & -4 & & & & $06: 10: 06$ & 4 & 123.9 & 0 & -4 & & \\
\hline & \multirow[b]{2}{*}{ 06:26:06 } & 6 & 122.9 & 0 & -6 & & & & 06:16:06 & 16 & 122.9 & 0 & -4 & & \\
\hline & & 17 & 121.9 & 0 & 6 & & & & $06: 30: 07$ & 17 & 121.9 & 0 & 6 & & \\
\hline & \multirow{2}{*}{ 06:31:06 } & 3 & 123.9 & 0 & -5 & & & & \multirow{2}{*}{ 06:31:06 } & 3 & 123.9 & 0 & -5 & & \\
\hline & & 2 & 123.9 & 0 & -5 & & & & & 2 & 123.9 & 0 & -5 & & \\
\hline & 06:33:06 & 10 & 121.9 & 0 & -2 & & & & 06:39:06 & 24 & 123.9 & 0 & -1 & & \\
\hline & 06:43:06 & 24 & 123.9 & 0 & -1 & & & & 06:43:06 & 6 & 122.9 & 0 & -6 & & \\
\hline & 06:44:06 & 16 & 124.9 & 0 & -2 & & & & $06: 45: 07$ & 10 & 121.9 & 0 & -2 & & \\
\hline & 07:02:06 & 1 & 123.9 & 0 & -1 & & & & 06:51:06 & 1 & 123.9 & 0 & -1 & & \\
\hline & 07:03:06 & 26 & 124.9 & 0 & 10 & & & & 07:03:06 & 26 & 124.9 & 0 & 10 & & \\
\hline & 07:05:06 & 25 & 124.9 & 0 & 10 & & & & 07:05:06 & 25 & 124.9 & 0 & 10 & & \\
\hline & 07:30:07 & 21 & 122.9 & 0 & -2 & 1 & 0 & & 07:29:06 & 21 & 122.9 & 0 & -2 & 1 & \\
\hline
\end{tabular}

Own calculations

( $->$ cheaper; $+\longrightarrow$ more expensive). For example, looking on dayround \#300, station 23 is still cheaper by $-1 \mathrm{ct}(€ 1.21)$ than station 21 with 1.22 at the time of price its price reduction to $€ 122.9$. Due to the fact that the former price of the price decreaser is also included in every price round, "pricediff" measures the price decreasing amount here. For example, station 21 had been 2 ct more expensive at 6.01:06 compared to a new price at 7:30:07. While the price differences in day round 300 are relatively small, they are relatively large in day round 301. The variable "Event" is used to assign the value 1 to each gas station that is the first to reduce its price. All other price announcements in the respective

Table 6 Relevant price announcements of the first three price reduction rounds on January 3, 2018

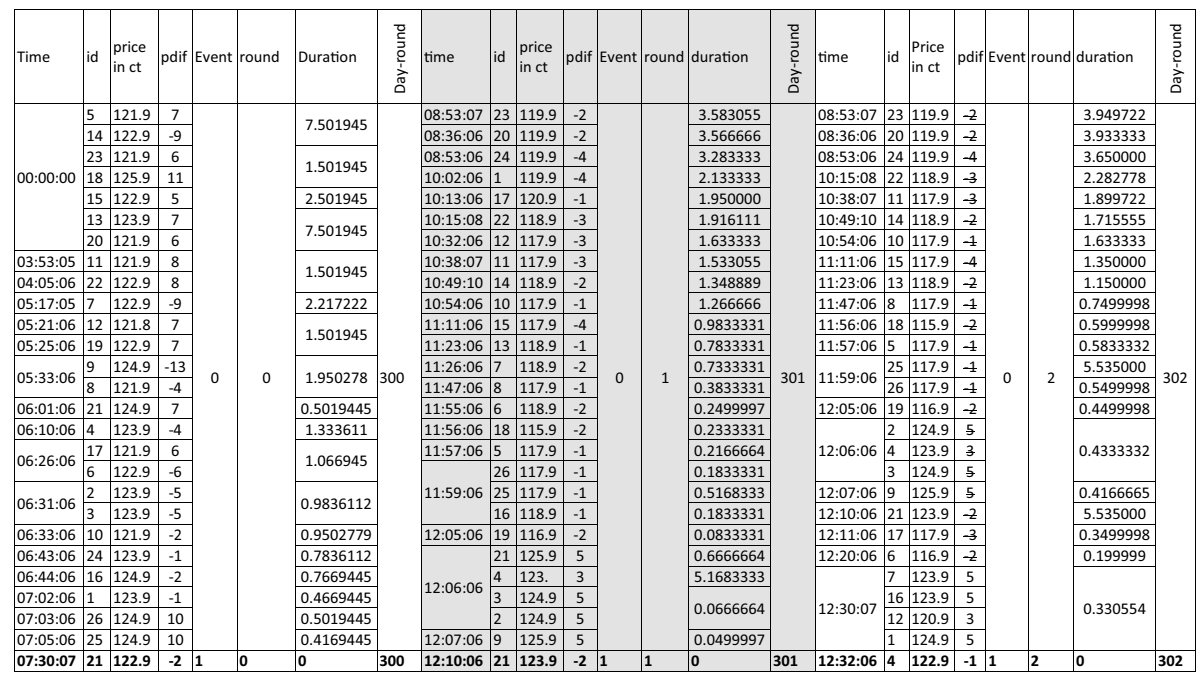

Own calculations 
Table 7 Example for final data record

\begin{tabular}{|c|c|c|c|c|c|c|c|c|c|c|c|c|c|c|c|c|c|}
\hline 品 & Time & id & 곡. & 묵 & 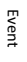 & $\begin{array}{l}\text { o } \\
\grave{\Xi} \\
\text { a }\end{array}$ & 产㰻 & 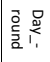 & 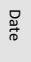 & Time & id & 꽁. & 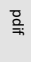 & $\stackrel{\overbrace{}}{\overparen{\prod}}$ & $\begin{array}{l}\text { ㅁ } \\
\grave{\Xi} \\
\text { aे }\end{array}$ & 拳 & 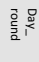 \\
\hline \multirow{27}{*}{ 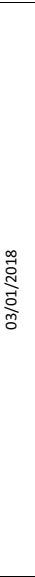 } & \multirow{7}{*}{$00: 00: 00$} & 23 & 121.9 & & \multirow{26}{*}{0} & \multirow{27}{*}{0} & -1 & \multirow{27}{*}{300} & \multirow{27}{*}{$\frac{\substack{\infty \\
\stackrel{N}{N}}}{\stackrel{-}{0}}$} & 08:53:07 & 23 & 119.9 & & \multirow{26}{*}{0} & \multirow{27}{*}{1} & -4 & \multirow{27}{*}{301} \\
\hline & & 15 & 122.9 & & & & 0 & & & \begin{tabular}{|l|}
$08: 36: 06$ \\
\end{tabular} & 20 & 119.9 & & & & -4 & \\
\hline & & 13 & 123.9 & & & & 1 & & & \begin{tabular}{|l|}
$08: 53: 06$ \\
\end{tabular} & 24 & 119.9 & & & & -4 & \\
\hline & & 14 & 122.9 & & & & 0 & & & \begin{tabular}{|l|}
$10: 02: 06$ \\
\end{tabular} & 1 & 119.9 & & & & -4 & \\
\hline & & 20 & 121.9 & & & & -1 & & & \begin{tabular}{|l|}
$10: 13: 06$ \\
\end{tabular} & 17 & 120.9 & & & & -3 & \\
\hline & & 18 & 125.9 & & & & 3 & & & \begin{tabular}{|l|}
$10: 15: 08$ \\
\end{tabular} & 22 & 118.9 & & & & -5 & \\
\hline & & 5 & 121.9 & & & & -1 & & & \begin{tabular}{|l|}
$10: 32: 06$ \\
\end{tabular} & 12 & 117.9 & & & & -6 & \\
\hline & \begin{tabular}{|l|}
$03: 53: 09$ \\
\end{tabular} & 11 & 121.9 & & & & -1 & & & \begin{tabular}{|l|}
$10.38: 07$ \\
\end{tabular} & 11 & 117.9 & & & & -6 & \\
\hline & \begin{tabular}{|l|}
$04: 05: 06$ \\
\end{tabular} & 22 & 122.9 & & & & 0 & & & \begin{tabular}{|l|}
$10: 49: 10$ \\
\end{tabular} & 14 & 118.9 & & & & -6 & \\
\hline & \begin{tabular}{|l|}
$05: 17: 05$ \\
\end{tabular} & 7 & 122.9 & & & & 0 & & & \begin{tabular}{|l|}
$10: 54: 06$ \\
\end{tabular} & 10 & 117.9 & & & & -6 & \\
\hline & \begin{tabular}{|l|}
$05: 21: 06$ \\
\end{tabular} & 12 & 121.9 & & & & -1 & & & \begin{tabular}{|l|}
$11: 11: 06$ \\
\end{tabular} & 15 & 117.9 & & & & -5 & \\
\hline & \begin{tabular}{|l|}
$05: 25: 06$ \\
\end{tabular} & 19 & 122.9 & & & & 0 & & & \begin{tabular}{|l|}
$11: 23: 06$ \\
\end{tabular} & 13 & 118.9 & & & & -5 & \\
\hline & \begin{tabular}{|l|}
$05: 33: 06$ \\
\end{tabular} & 9 & 124.9 & & & & 2 & & & \begin{tabular}{|l|}
$11: 26: 06$ \\
\end{tabular} & 7 & 118.9 & & & & -6 & \\
\hline & \begin{tabular}{|l|}
$05: 33: 06$ \\
\end{tabular} & 8 & 122.9 & & & & -1 & & & 11:47:06 & 8 & 117.9 & & & & -5 & \\
\hline & \begin{tabular}{|l|}
$06: 01: 06$ \\
\end{tabular} & 21 & 124.9 & & & & 2 & & & \begin{tabular}{|l|}
$11: 55: 06$ \\
\end{tabular} & 6 & 118.9 & & & & -8 & \\
\hline & \begin{tabular}{|l|}
$06: 10: 06$ \\
\end{tabular} & 4 & 123.9 & & & & 1 & & & \begin{tabular}{|l|}
$11: 56: 06$ \\
\end{tabular} & 18 & 115.9 & & & & -6 & \\
\hline & \begin{tabular}{|l|}
$06: 26: 06$ \\
\end{tabular} & 17 & 121.9 & & & & -1 & & & \begin{tabular}{|l|}
$11: 57: 06$ \\
\end{tabular} & 5 & 117.9 & & & & -6 & \\
\hline & \begin{tabular}{|l|}
$06: 26: 06$ \\
\end{tabular} & 6 & 122.9 & & & & 0 & & & \begin{tabular}{|l|}
$11: 59: 06$ \\
\end{tabular} & 25 & 117.9 & & & & -6 & \\
\hline & \begin{tabular}{|l|}
$06: 31: 06$ \\
\end{tabular} & 3 & 123.9 & & & & 1 & & & \begin{tabular}{|l|}
$11: 59: 06$ \\
\end{tabular} & 26 & 117.9 & & & & -5 & \\
\hline & \begin{tabular}{|l|}
$06: 31: 06$ \\
\end{tabular} & 2 & 123.9 & & & & 1 & & & \begin{tabular}{|l|}
$11: 59: 06$ \\
\end{tabular} & 16 & 118.9 & & & & -7 & \\
\hline & \begin{tabular}{|l|}
$06: 33: 06$ \\
\end{tabular} & 10 & 121.9 & & & & -1 & & & \begin{tabular}{|l|}
$12: 05: 06$ \\
\end{tabular} & 19 & 116.9 & & & & 1 & \\
\hline & \begin{tabular}{|l|}
$06: 43: 06$ \\
\end{tabular} & 24 & 123.9 & & & & 1 & & & \begin{tabular}{|l|}
$12: 06: 06$ \\
\end{tabular} & 2 & 124.9 & & & & 2 & \\
\hline & \begin{tabular}{|l|}
$06: 44: 06$ \\
\end{tabular} & 16 & 124.9 & & & & 2 & & & \begin{tabular}{|l|}
$12: 06: 06$ \\
\end{tabular} & 21 & 125.9 & & & & 1 & \\
\hline & \begin{tabular}{|l|}
$07: 02: 06$ \\
\end{tabular} & 1 & 123.9 & & & & 1 & & & \begin{tabular}{|l|}
$12: 06: 06$ \\
\end{tabular} & 3 & 124.9 & & & & 1 & \\
\hline & \begin{tabular}{|l|}
$07: 03: 06$ \\
\end{tabular} & 26 & 124.9 & & & & 2 & & & \begin{tabular}{|l|}
$12: 06: 06$ \\
\end{tabular} & 4 & 123.9 & & & & 0 & \\
\hline & \begin{tabular}{|l|}
$07: 05: 06$ \\
\end{tabular} & 25 & 124.9 & & & & 2 & & & \begin{tabular}{|l|}
$12: 07: 06$ \\
\end{tabular} & 9 & 125.9 & & & & 2 & \\
\hline & \begin{tabular}{|l|}
$07: 30: 07$ \\
\end{tabular} & 21 & 122.9 & -2 & 1 & & 0 & & & \begin{tabular}{|l|}
$12: 10: 06$ \\
\end{tabular} & 21 & 123.9 & -2 & 1 & & 0 & \\
\hline
\end{tabular}

Own calculations

price reduction round are attributed the value 0 . Transferred to all price reduction rounds, this results in the decisive dependent variable that is used for further analysis.

The variable "pricediff" might not exactly measure the basic idea of the paper-that each of the petrol stations surveyed could have reacted to this "market equilibrium," since there is complete market transparency through the data of MTU. Hence, an alternative price difference can be calculated: "pricedifft." For the very first observed price round on January 3, 2018, as already mentioned above, petrol station 21 reduced its price by $2 \mathrm{ct}$ at 7:30:07 (pdif in Table 8). The variable "pricedifft" takes the former price of the price decreaser reference point (here $124.9 \mathrm{ct}$ at 6:01:06, station 21) and calculates the price differences to the competitors. Inspecting Table 8, filling station 13 was thus $1 \mathrm{ct}$ cheaper than the price reducer before the price reduction, filling station 23 even $3 \mathrm{ct}$. In contrast, petrol station 18 was $1 \mathrm{ct}$ more expensive. Hence, negative values indicate that competitors had been cheaper and positive means competitors had been more expensive. "pricedifft" measures the price pressure which had been observable before the price decrease and might be the cause for price reduction. Expensive (positive values) and cheaper (negative values) stations can cancel each other out, and petrol stations with the same price can enter with 0 . (pricedifft are artificially imputed as 0 in case of the price decreaser's observation, meaning that the new price can have no influence on the perceived price pressure.) As a third alternative, in order to map only the price pressure of the cheaper petrol stations, expensive petrol stations were set to 0 for the variable "pricediffb," here petrol station 18. All three methods of difference calculation are economically arguable and will be considered-at least for the descriptive part.

Methodologically, then, the objective of this paper is to explain why a gas station is the first to lower its price after price increases (pricediff/pricedifft/pricediffb $=1$ ) compared to all other gas stations that do not lower their price at that exact time (pricediff/pricedifft/ pricediff $b=0$ ). Thus, a logit estimation can be applied as a regression model. Assigning the prices that were in effect prior to the round of price cuts results in one panel observation unit at a time; a novel panel data set created for this question is calculated from the 
Table 8 Alternative concepts for price pressure

\begin{tabular}{|c|c|c|c|c|c|c|c|}
\hline Time & Id & Price in ct & pdif & Event & pricediff & pricedifft & pricediffb \\
\hline \multirow[t]{7}{*}{ 00:00:00 } & 13 & 123.9 & & 0 & 1 & -1 & 1 \\
\hline & 5 & 121.9 & & & -1 & -3 & -3 \\
\hline & 23 & 121.9 & & & 0 & -1 & -3 \\
\hline & 14 & 122.9 & & & 0 & -2 & -2 \\
\hline & 20 & 121.9 & & & -1 & -3 & -3 \\
\hline & 18 & 125.9 & & & 3 & 1 & 0 \\
\hline & 15 & 122.9 & & & 0 & -2 & -2 \\
\hline 03:53:05 & 11 & 121.9 & & & -1 & -3 & -3 \\
\hline 04:05:06 & 22 & 122.9 & & & 0 & -2 & -2 \\
\hline 05:17:05 & 7 & 122.9 & & & 0 & -2 & -2 \\
\hline 05:21:06 & 12 & 121.9 & & & -1 & -3 & -3 \\
\hline 05:25:06 & 19 & 122.9 & & & 0 & -2 & -2 \\
\hline \multirow[t]{2}{*}{ 05:33:06 } & 9 & 124.9 & & & 2 & 0 & 0 \\
\hline & 8 & 121.9 & & & -1 & -3 & -3 \\
\hline 06:01:06 & 21 & 124.9 & & & 2 & 0 & 0 \\
\hline 06:10:06 & 4 & 123.9 & & & 1 & -1 & -1 \\
\hline \multirow[t]{2}{*}{$06: 26: 06$} & 6 & 122.9 & & & 0 & -2 & -2 \\
\hline & 17 & 121.9 & & & -1 & -3 & -3 \\
\hline \multirow[t]{2}{*}{$06: 31: 06$} & 2 & 123.9 & & & 1 & -1 & -1 \\
\hline & 3 & 123.9 & & & 1 & -1 & -1 \\
\hline $06: 33: 06$ & 10 & 121.9 & & & -1 & -3 & -3 \\
\hline $06: 43: 06$ & 24 & 123.9 & & & 1 & -1 & -1 \\
\hline $06: 44: 06$ & 16 & 124.9 & & & 2 & 0 & 0 \\
\hline 07:02:06 & 1 & 123.9 & & & 1 & -1 & -1 \\
\hline 07:03:06 & 26 & 124.9 & & & 2 & 0 & 0 \\
\hline 07:05:06 & 25 & 124.9 & & & 2 & 0 & 0 \\
\hline 07:30:06 & 21 & 122.9 & -2 & 1 & 0 & - & - \\
\hline
\end{tabular}

Diesel, 01/03/2018, own calculations

multiple application of this assignment mechanism. A maximum of 26 petrol stations are included as observation characteristics, 363 days count for 2018 and 365 days for 2019, in sum 728 days. In total, a maximum of 37 laps per day were recorded. The panel could therefore contain $37 * 728=26,936$ observations, but in fact 37 laps did not occur on all days. The panel therefore comprises only 10,918 observations. Theoretically, one would expect gas stations to respond to price pressure from their competitors (relatively lower prices), here measured as direct price differences or weighted by the duration of the price difference or the distance to the competing gas station. Control variables include the brand affiliation of the gas station, the number or specific service offerings, the opening hours, the location of the gas station (in sight of a competitor, close to a state highway or freeway, on specific commuter routes, weekdays and vacations, in the city of Lueneburg or outside), or general satisfaction with the gas station. Since in each price reduction round a different gas station may initiate the first price reduction and then all other gas stations did not react to the given price situation, the station-specific control variables change in the panel observation units too. In this respect, gas station characteristics can be directly included in 
the estimation in a fixed-effects model. In order to account for non-observable factors influencing the respective service station, such as different demands for fuel depending on the typical traffic situation or the immediate environment, station-specific fixed effects can also be estimated; as long as these do not change over time, they can be controlled for without having variables for them.

\section{Descriptive Results}

In the final modified data set, 10,918 diesel price reduction events were defined (Table 9). Three-quarters of all events refer to relatively small reductions of 1 or $2 \mathrm{ct}$. A little bit less than half are only price reductions of $1 \mathrm{ct}$. Larger price reductions are therefore relatively rare, and the "probability" decreases as the amount increases.

Table 10 gives an overview of how often the respective petrol station is the first to reduce prices in the daily rounds (in detail Appendix Tables 23 and 24). In the first round (round \#0) of the respective days, petrol station 16 (Shell in Barowick) initiated the downward price movement with roughly $17 \%$ of all 728 first price round events. Esso in Lueneburg (petrol station 6) contributed about 13\%, and Shell in Melbeck (station \#24) had a share of one-tenth. Inspecting the following price reduction events up to round 9, it is remarkable that all stations are responsible for being the first to leave the paradise on various days. The highest shares (between 5 and 10\%) can be observed for Aral (\# 2, 4, 9) and Shell (\# 14, 16). The number of price round events is decreasing in the course of the day. The detailed tables in the Appendix also show this decreasing trend, with the number of

Table 9 Frequency and extent of price reduction events

\begin{tabular}{lll}
\hline Price decreases & Frequencies & Percent \\
\hline-19 & 2 & 0.02 \\
-18 & 1 & 0.01 \\
-17 & 2 & 0.02 \\
-15 & 2 & 0.02 \\
-14 & 2 & 0.02 \\
-13 & 4 & 0.04 \\
-12 & 3 & 0.03 \\
-11 & 4 & 0.04 \\
-10 & 25 & 0.23 \\
-9 & 52 & 0.48 \\
-8 & 119 & 1.09 \\
-7 & 191 & 1.75 \\
-6 & 336 & 3.08 \\
-5 & 382 & 3.50 \\
-3.9 and 4 & 860 & 7.88 \\
-3 & 979 & 8.97 \\
-2 & 2,991 & 27.40 \\
-1 & 4,963 & 45.46 \\
& 10,918 & 100.00 \\
\hline
\end{tabular}

Own calculations 
Table 10 Percentages of price decreasers/first 10 rounds

\begin{tabular}{|c|c|c|c|c|c|c|c|c|c|c|c|c|c|}
\hline \multirow[b]{2}{*}{ Id } & \multirow[b]{2}{*}{ Brand } & \multirow[b]{2}{*}{ Street } & \multirow[b]{2}{*}{ Place } & \multicolumn{10}{|c|}{ Round } \\
\hline & & & & 0 & 1 & 2 & 3 & 4 & 5 & 6 & 7 & 8 & 9 \\
\hline & & & & \multicolumn{10}{|c|}{$\%$} \\
\hline 1 & Shell & \multirow{2}{*}{ Universitätsallee } & \multirow{15}{*}{ Lueneburg } & 2.5 & 5.8 & 4.3 & 3.2 & 4.6 & 3.8 & 3.4 & 3.3 & 3.8 & 2.9 \\
\hline 2 & \multirow{3}{*}{ ARAL } & & & 3.9 & 8.5 & 8.4 & 8.0 & 6.1 & 5.6 & 5.4 & 4.0 & 4.4 & 5.6 \\
\hline 3 & & Soltauer Str. & & 3.4 & 5.0 & 6.3 & 6.5 & 5.3 & 4.6 & 5.9 & 6.6 & 4.1 & 5.1 \\
\hline 4 & & \multirow{2}{*}{$\begin{array}{l}\text { Dahlenburger } \\
\text { Landstr. }\end{array}$} & & 5.0 & 6.7 & 9.9 & 7.7 & 7.6 & 8.4 & 8.0 & 7.2 & 8.2 & 8.1 \\
\hline 5 & LTG & & & 1.3 & 3.4 & 2.4 & 3.7 & 2.9 & 2.1 & 1.3 & 2.1 & 1.1 & 1.4 \\
\hline 6 & ESSO & Bleckeder Landstr. & & 13.1 & 2.6 & 3.0 & 3.2 & 3.9 & 5.0 & 4.3 & 6.0 & 4.7 & 4.7 \\
\hline 7 & Shell & Erbstorfer Landstr. & & 6.6 & 3.9 & 4.5 & 4.8 & 5.0 & 3.9 & 3.7 & 3.3 & 3.6 & 5.2 \\
\hline 8 & STAR & Auf den Bloecken & & 1.1 & 2.6 & 1.1 & 1.7 & 0.7 & 0.4 & 0.9 & 1.5 & 0.6 & 0.8 \\
\hline 9 & ARAL & Hamburger Str. & & 5.4 & 6.6 & 6.3 & 5.2 & 6.5 & 7.1 & 4.6 & 5.3 & 5.7 & 4.6 \\
\hline 10 & Hoyer & Bessemer Str & & 3.2 & 5.2 & 4.4 & 4.4 & 3.0 & 2.7 & 3.4 & 1.1 & 2.5 & 2.0 \\
\hline 11 & HEM & $\begin{array}{l}\text { Vor dem Neuen } \\
\text { Tore }\end{array}$ & & 1.5 & 3.0 & 2.1 & 2.2 & 1.7 & 2.1 & 2.3 & 2.7 & 3.5 & 2.9 \\
\hline 12 & $B f t$ & Am Grasweg & & 2.8 & 2.6 & 2.8 & 2.8 & 3.9 & 3.5 & 3.0 & 4.5 & 4.7 & 3.5 \\
\hline 13 & $\begin{array}{l}\text { Beck- } \\
\text { mann/Lin. }\end{array}$ & Auf der Hude & & 2.5 & 2.1 & 3.3 & 1.8 & 1.2 & 1.8 & 1.0 & 0.6 & 2.1 & 1.0 \\
\hline 14 & Shell & $\begin{array}{l}\text { Vor dem } \\
\text { Bardowicker Tore }\end{array}$ & & 1.1 & 4.0 & 4.5 & 4.1 & 7.3 & 8.7 & 8.3 & 10.2 & 10.4 & 10.3 \\
\hline 15 & \begin{tabular}{|l|} 
Freie \\
Tankstelle
\end{tabular} & Hamburger Str. & & 0.3 & 0.4 & 1.1 & 1.2 & 1.4 & 0.6 & 0.6 & 0.2 & 0.5 & 0.8 \\
\hline 16 & Shell & & & 17.2 & 6.2 & 5.5 & 4.3 & 5.1 & 6.1 & 6.6 & 5.1 & 5.2 & 7.1 \\
\hline 17 & \begin{tabular}{|l} 
Freie \\
Tankstelle \\
Salewski
\end{tabular} & Hamburger Landstr. & Bardowick & 2.8 & 2.6 & 2.3 & 1.8 & 1.4 & 1.1 & 1.3 & 0.8 & 2.7 & 1.9 \\
\hline 18 & JET & $\begin{array}{l}\text { Artlenburger } \\
\text { Landstr. }\end{array}$ & Adendorf & 2.6 & 4.0 & 2.2 & 2.5 & 1.9 & 1.8 & 0.4 & 1.1 & 0.6 & 1.7 \\
\hline 19 & Shell & Bueltenweg & & 1.4 & 1.9 & 2.5 & 5.4 & 2.8 & 6.6 & 5.4 & 3.6 & 6.2 & 4.4 \\
\hline 20 & Raiffeisen & Raiffeisenstr. & $\begin{array}{l}\text { Scharne- } \\
\text { beck }\end{array}$ & 1.2 & 1.7 & 1.8 & 2.1 & 1.5 & 1.5 & 1.4 & 2.0 & 1.3 & 1.7 \\
\hline 21 & ARAL & Bundesstr. & Brietlingen & 4.3 & 5.0 & 4.4 & 4.8 & 6.9 & 4.6 & 5.4 & 6.3 & 4.0 & 4.9 \\
\hline 22 & Shell & Lueneburger Str. & $\begin{array}{l}\text { Kirch- } \\
\text { gellersen }\end{array}$ & 3.2 & 7.3 & 6.2 & 8.1 & 8.7 & 8.0 & 10.4 & 11.3 & 9.9 & 10.9 \\
\hline 23 & Raiffeisen & Lueneburger Str. & Barendorf & 2.6 & 3.2 & 4.3 & 4.4 & 2.6 & 1.7 & 2.4 & 3.5 & 2.5 & 1.4 \\
\hline 24 & Shell & Uelzener Str. & Melbeck & 10.2 & 3.7 & 3.6 & 2.9 & 4.8 & 4.3 & 6.0 & 5.4 & 4.7 & 5.9 \\
\hline 25 & \multirow[t]{2}{*}{ LTG } & Timelostr. & \begin{tabular}{|l|} 
Deutsch \\
Evern
\end{tabular} & 1.1 & 0.7 & 1.7 & 1.7 & 1.9 & 2.4 & 2.4 & 1.4 & 1.4 & 1.0 \\
\hline 26 & & Bahnhofstr. & Embsen & 0.3 & 1.5 & 1.4 & 1.8 & 1.2 & 1.5 & 2.0 & 0.6 & 1.7 & 0.5 \\
\hline \multicolumn{4}{|c|}{ Sum of price decreasers } & 728 & 728 & 728 & 727 & 723 & 717 & 699 & 667 & 635 & 594 \\
\hline \multicolumn{14}{|c|}{ Weighted shares for brands with at least two service stations: } \\
\hline \multicolumn{4}{|c|}{ Shell (7 stations) } & 6.5 & 5.5 & 5.2 & 5.5 & 6.2 & 6.9 & 7.3 & 7.1 & 5.7 & 6.8 \\
\hline \multicolumn{4}{|c|}{ ARAL (5 stations) } & 4.4 & 6.4 & 7.1 & 6.4 & 6.5 & 6.1 & 5.9 & 5.9 & 5.3 & 5.7 \\
\hline \multicolumn{4}{|c|}{ LTG (3 stations) } & 0.9 & 1.9 & 1.8 & 2.4 & 2.1 & 2.0 & 1.9 & 1.4 & 1.4 & 1.0 \\
\hline \multicolumn{4}{|c|}{ Raiffeisen (2 stations) } & 0.8 & 1.1 & 1.6 & 2.0 & 1.4 & 1.6 & 1.7 & 1.3 & 1.5 & 1.1 \\
\hline
\end{tabular}

Diesel. Own calculations with Stata 16.0

rounds approaching 0 for the last few rounds, as was to be expected. In the last, the 36th round, there is only one price reduction event. If the individual gas stations are summarized at brand level, i.e., not taking individual suppliers into account, and weighted with the number of gas stations occurring in the Lueneburg region, Aral and Shell each contribute about 5\% to the effect of being the first to lower prices in the first eleven price reduction rounds after previous price increases. The small brands "LTG" and "Raiffeisen," on the other hand, play almost no role in this form of price dynamics. The average values are 
calculated as an arithmetic mean of the existing petrol stations so that they do not add up to 100 .

The generated dataset is described by using Tables 11 and 12. According to Table 11, the average price messages correspond to a value of $126 \mathrm{ct}$ for diesel, with a standard deviation of 5.9 ct. The lowest price in the observation period was 108.9 and the highest 151.9 ct. A total of slightly less than 300,000 observations were included in the data set. The average price differences can be calculated differently, as already explained above.

First, if one compares the previous average prices of the competitors and the price reducer, with the new price of the price reducer at the reduction event (pricediff), there is almost no average deviation $(0.06 \mathrm{ct})$ at a standard deviation of $4.13 \mathrm{ct}$. The latter points

Table 11 Descriptives I-data set

\begin{tabular}{|c|c|c|c|c|}
\hline & Mean & $\mathrm{Sd}$ & Min & $\operatorname{Max}$ \\
\hline Announced prices & 126.0 & 5.9 & 108.9 & 151.9 \\
\hline \multicolumn{5}{|l|}{ Price differences } \\
\hline $\begin{array}{l}\text {-Average prices before price decreasing versus decreased price (pri- } \\
\text { cediff) }\end{array}$ & 0.06 & 4.13 & -25 & 25 \\
\hline $\begin{array}{l}\text {-Average prices before price decreasing versus price of decreasers } \\
\text { before its price decreasing (pricedifft) }\end{array}$ & -2.09 & 4.04 & -27 & 21 \\
\hline $\begin{array}{l}\text {-Average prices before price decreasing versus price of decreasers } \\
\text { before its price decreasing; more expensive excluded (pricediffb) }\end{array}$ & -2.70 & 10.51 & -27 & 0 \\
\hline Duration of prices & 1.29 & 2.09 & 0.5 & 17.50 \\
\hline \multicolumn{5}{|l|}{ Local competition } \\
\hline \multicolumn{5}{|l|}{ Prices of non-decreasers versus decreased price } \\
\hline -To nearest competitor & -1.00 & 11.14 & -140.8 & 109.8 \\
\hline -To second nearest competitor & -0.67 & 15.10 & -193.2 & 123.5 \\
\hline -To third nearest competitor & -0.79 & 16.52 & -183.3 & 142.5 \\
\hline \multicolumn{5}{|l|}{ Prices of non-decreasers versus before price of non-decreasers } \\
\hline -To nearest competitor & -6.31 & 11.29 & -153.6 & 0 \\
\hline -To second nearest competitor & -9.23 & 14.24 & -218.4 & 0 \\
\hline -To third nearest competitor & -10.40 & 15.28 & -210.6 & 0 \\
\hline \multicolumn{5}{|c|}{ Prices of non-decreasers versus before price of non-decreasers; more expensive excluded } \\
\hline -To nearest competitor & -5.41 & 12.30 & -153.6 & 103.70 \\
\hline -To second nearest competitor & -9.23 & 14.24 & -218.4 & 115.6 \\
\hline -To third nearest competitor & -10.40 & 15.28 & -210.6 & 132.6 \\
\hline \multicolumn{5}{|l|}{ Additional variables } \\
\hline Number of services & 3.30 & 1.64 & 0 & 6 \\
\hline Number of accepted credit cards & 3.62 & 1.92 & 0 & 5 \\
\hline Rounds per day & 8.69 & 6.61 & 0 & 36 \\
\hline Customer satisfaction & 4.07 & 0.35 & 3.4 & 4.8 \\
\hline \multicolumn{5}{|l|}{ Opening hours } \\
\hline Mondays to Fridays & 20.72 & 4.05 & 12 & 24 \\
\hline Saturdays & 20.35 & 4.83 & 6 & 24 \\
\hline Sundays and public holidays & 19.9 & 5.87 & 0 & 24 \\
\hline
\end{tabular}

293,902 observations for all variables without consumer satisfaction (277,316); diesel only. Calculated with Stata 16 
Table 12 Descriptives II-data set

\begin{tabular}{|c|c|c|c|}
\hline & Mean & Min & $\operatorname{Max}$ \\
\hline \multicolumn{4}{|l|}{ Location } \\
\hline Near national roads? & 0.24 & 0 & 1 \\
\hline Near motorways? & 0.04 & 0 & 1 \\
\hline Shell/Aral Universitaetsallee? & 0.08 & 0 & 1 \\
\hline Commuter route Lueneburg North? & 0.15 & 0 & 1 \\
\hline Commuter route Lueneburg Middle? & 0.08 & 0 & 1 \\
\hline Commuter route Gellersen? & 0.12 & 0 & 1 \\
\hline Commuter route Uelzen? & 0.12 & 0 & 1 \\
\hline Commuter route Dahlenburg? & 0.16 & 0 & 1 \\
\hline Rural? & 0.41 & 0 & 1 \\
\hline \multicolumn{4}{|l|}{ Market structure } \\
\hline Aral? & 0.18 & 0 & 1 \\
\hline Shell? & 0.28 & 0 & 1 \\
\hline Non-Oligopolists1? & 0.27 & 0 & 1 \\
\hline Non-Oligopolists2? & 0.14 & 0 & 1 \\
\hline \multicolumn{4}{|l|}{ Services } \\
\hline ATM? & 0.16 & 0 & 1 \\
\hline Bistro? & 0.42 & 0 & 1 \\
\hline Car repair? & 0.32 & 0 & 1 \\
\hline Car wash? & 0.44 & 0 & 1 \\
\hline In-store-bakery? & 0.20 & 0 & 1 \\
\hline Kiosk? & 0.05 & 0 & 1 \\
\hline Rewe to Go? & 0.08 & 0 & 1 \\
\hline Self service station? & 0.22 & 0 & 1 \\
\hline Shop? & 0.77 & 0 & 1 \\
\hline Toilet? & 0.56 & 0 & 1 \\
\hline Vacuum cleaner? & 0.32 & 0 & 1 \\
\hline \multicolumn{4}{|l|}{ Days } \\
\hline Mondays? & 0.16 & 0 & 1 \\
\hline Tuesdays? & 0.15 & 0 & 1 \\
\hline Wednesdays? & 0.15 & 0 & 1 \\
\hline Thursdays? & 0.15 & 0 & 1 \\
\hline Fridays? & 0.14 & 0 & 1 \\
\hline Saturdays? & 0.13 & 0 & 1 \\
\hline Sundays and public holidays & 0.11 & 0 & 1 \\
\hline Holidays & 0.32 & 0 & 1 \\
\hline
\end{tabular}

293,503 observations; diesel only, calculated with Stata 16.0

to special events; however, if one takes the average price pressure of the decreaser, which was exposed up to one second before the price reduction (pricedifft), the prices were on average slightly more than 2 ct lower; standard deviation and extreme values hardly change. If one considers the average price pressure before the price reduction as the price difference, and assumes that more expensive petrol stations do not exert any price pressure (pricediffb), the average price difference increases to $2.7 \mathrm{ct}$. Combined 
with a significantly higher standard deviation of over $10 \mathrm{ct}$, the lower extreme value remains the same and the maximum is, by definition, 0. The average duration of all competitors' prices within the price reduction rounds is 1.29 machine hours. The price differences to the next, second, or third closest competitors (see Table 19 in the Appendix), weighted by the distance between the petrol stations, can also exert price pressure and thus motivate price reductions. If one takes the price of the price reducer after the price reduction as a benchmark, the next closest suppliers are on average exactly $1 \mathrm{ct}$ cheaper. The second closest is $0.67 \mathrm{ct}$ cheaper, and the third closest $0.79 \mathrm{ct}$ cheaper. If, however, one takes the prices of the price reducer before the reduction as a benchmark, the next (second-next/third-next) petrol stations were on average $6.3(9.2 / 10.4)$ ct cheaper. Assuming that only cheaper petrol stations exert pressure before the price reduction event, the nearest petrol stations charge $5.4 \mathrm{ct}$ less. By contrast, the second or third closest competitors are on average about $10 \mathrm{ct}$ cheaper. In summary, if the benchmark is set at the price of the price reducer before reduction, there was considerable price pressure from competitors. That pressure was preceded by a price reduction, irrespective of whether the absolute price differences, the time-weighted differences, or the differences to the next three petrol stations were taken as a basis. On average, the petrol stations offer 3.3 services, slightly less than nine price reduction rounds per day were defined, and the average customer satisfaction was 4.1, albeit with little variance. The petrol stations have an average of $20.7 \mathrm{~h}$ open during the week, slightly less on Saturdays and slightly less on Sundays and public holidays with just under $20 \mathrm{~h}$ if one refers to the price reduction rounds recorded in the data set.

Descriptive evaluations of dummy variables of the data set can be found in Table 11. The petrol stations located on the main road account for almost a quarter of all prices recorded, whereas the only petrol station located directly on the motorway access road only accounts for less than a twentieth of the data set. Less than 1/10 concern price reports from Aral and Shell in Universitätsallee, which are within sight of each other. Of the approximately 300,000 price announcements, $15 \%$ are located on the commuter route (see Appendix Table 21) towards Dahlenburg; 12\% can be allocated to the routes towards Gellersen and Uelzen, and 15 and 8\%, respectively, are on the way to the motorway entrance "Lueneburg-North" and to the entrance "Lueneburg-Middle." About two-fifths of all price reports concern petrol stations outside the Lüneburg city area. In regard to market-structural factors, it should be noted that almost one-fifth of prices are due to Aral petrol stations. Shell is represented with almost $30 \%$ and the non-oligopolists 1 with one quarter. The independent local Non-Oligopolists 2 occurs in roughly $15 \%$ of all cases. If the service variables are taken up:

- The four petrol stations with ATMs contribute $16 \%$ of the price reports,

- Petrol stations with bistros $42 \%$,

- Petrol stations with car repair shops $32 \%$,

- With car washes almost half,

- With back shop one-fifth,

- With kiosk 5\%,

- With REWE to Go 8\%,

- As self-service stations $22 \%$,

- With shop three quarters,

- With toilets $56 \%$, and

- With vacuum cleaners $32 \%$ 
of the data set. The days of the week are distributed more or less equally, and holidays concern one-third of all price announcements.

\section{Multivariate Results}

Multivariate estimations will now be applied to examine which possible influencing factors explain the willingness of a petrol station to be the first to lower the price. As shown above, most price reductions are made in the 1-2 ct range. Consequently, it is obvious to specify the dependent variable as a dummy variable, whereby price reduction at the respective petrol station is defined as 1 , and non-price reduction takes on the value 0 . In each model, the point estimators of the respective coefficients are given exactly, and in brackets the t-values of the coefficients for estimating the statistical quality. In addition, the marginal average effects are shown in dashes in order to estimate the economically relevant size effects. Tables 13, 14, 15, and 16 and Appendix Table 23 show the results of the estimation if individual independent variables are gradually included in the estimation equation or-to avoid problems such as multicollinearity-replaced by others; estimation with all explanatory variables is impossible because the matrix to be estimated is not invertible. For all independent variables relating to price differences, the prices of the non-lowering petrol stations are compared with the price of the price-reducing petrol station before the latter decides to deviate downwards (pricedifft, see Table 8), as this difference is probably the most plausible economic expression of the price pressure for the price reducer.

Table 13 looks separately at the influence of price differences, brand affiliation, and the location of the petrol stations in order to determine the probability of a petrol station initiating a price reduction round. According to estimation model 1, the absolute price difference between the average prices of all non-lowering petrol stations, and the price of the lowering supplier, causes an increased probability of price reduction at the highest significance level. The marginal average effect that competitors would offer was on average $1 \mathrm{ct}$ cheaper than the sinking supplier was at five percentage points. Since price differences are mostly very small, this independent variable has a relatively small economic impact. Even smaller is the time-weighted influence of the price difference on the likelihood of a reduction, according to which the again highly significant positive coefficient increases the probability of leaving the price paradise. If competitors become 1 cent cheaper and this price difference applies for $1 \mathrm{~h}$, the probability of a price reduction increases by only 0.4 percentage points (pp). To this extent, the two independent variables that are solely based on the price differences may provide a significant statistical explanation, but in economic terms these effects are relatively small. It is precisely the theory of the Edgeworth cycles with price differences as an "undercutting" explanatory factor that would see a major influence here. Later, it should be examined whether the results change when the proximity of petrol stations to each other is combined with the price differences. Model 1 incorporates close to 300,000 observations with over 11,000 rounds of price reductions. With a high $\mathrm{X}^{2}$-value, the likelihood ratio test rejects the null hypothesis that the estimated coefficients, with the exception of the constants, have no explanatory force for the initiation of price reduction rounds; in this respect, the model can make a contribution to the intraday price-setting behavior of service stations with a very high probability. Estimation model 2 deals with the market structure effects. In the fixed-effect model, the change of a petrol station to the Aral brand would increase the probability of becoming a price reducer by $19 \mathrm{pp}$ (highly significant coefficient). Switching to the Shell brand would also significantly increase the probability 
Table 13 Fixed-effect-logit-price differences, market structure, and location effects

(1) (2)

2)

(3)

\begin{tabular}{ll}
\hline Price difference to price sinker, compared to price before & $0.219^{* * *}$ \\
$|0.05|$ & $(0.004)$ \\
Price difference * duration; measured in machine h & $0.0173^{* * *}$ \\
$|0.004|$ & $(0.0004)$
\end{tabular}

Aral?

Shell?

Non-oligopolist, nation

Stations in rural area?

In sight?

Commuter route to

Motorway exit Lueneburg-North?

Motorway exit Lueneburg-Middle?

Direction West (Gellersen)?

Direction South (Uelzen)?

Direction East (Dahlenburg)?
$0.760^{\text {**** }}$
$|0.19|$
(0.036)
$0.576^{\text {**** }}$
$10.14 \mid$
(0.035)
$-0.357^{* * *}$
$|-0.89|$
(0.04)
$-0.306^{* * *}$
$|-0.78|$
(0.045)

$$
\begin{aligned}
& -0.284^{* * *} \\
& |-0.070| \\
& (0.0277) \\
& -0.350^{* * *} \\
& |-0.086| \\
& (0.058)
\end{aligned}
$$

$-0.0132$

$|-0.003|$

(0.033)

$-0.421^{* * *}$

|-0.104|

(0.042)

$0.132^{* * *}$

$10.033 \mid$

(0.031)

$0.459^{* * *}$

|0.114|

(0.051)

$-0.324^{* * * *}$

| -0.080 |

(0.034)

$-0.0898^{*}$

$|-0.022|$

(0.0371)

$-0.472^{* * * *}$

$|-0.117|$

(0.060) 
Table 13 (continued)

(1)

LR-Test $\mathrm{X}^{2}$

( $p$ values)

Observations

Groups
5646.96

(0.000)

293,798

11,375
(2)

$2317.69(0.000)$

293,798

11,375
(3)

488.94 (0.000)

293,798

11,375

Dependent variable: within one round: $1=$ decreasing price observ., $0=$ non-decreasing price observ. Standard errors in parentheses; ${ }^{*} p<0.05,{ }^{* *} p<0.01,{ }^{* * *} p<0.001$. Values in $\|$ marginal average effects. Own calculations by using Stata 16.0

of becoming a price reducer, by $14 \mathrm{pp}$ to be precise. On the other hand, switching a petrol station to non-oligopolistic brands, being nationally operating brands or local, independent suppliers, would drastically reduce the probability of a reduction. In the case of switching to non-oligopolistic nationwide brands, the probability of reduction would decrease by $89 \mathrm{pp}$, and by $78 \mathrm{pp}$ for local independent brands, both underlying negative coefficients are secured at the 1/1000 significance level. According to the second estimation model, it is the big brands that are the first to lower prices. Even more importantly, the non-oligopolists have no interest in acting as price breakers. If, according to estimation model 3, we only look at the location of price-reducing petrol stations, the following explanatory factors have a negative influence on the probability of a reduction. Assuming a petrol station from Lueneburg area instead of Lueneburg city reduces the probability of leaving the paradise by 7 pp, and being near Aral and Shell in Lueneburger Universitaetsallee by 8.6 pp, to have a station on the commuter route to Lueneburg-Mitte at $10.4 \mathrm{pp}$ and to Dahlenburg at $8 \mathrm{pp}$, to assume a station on a federal road at $2.2 \mathrm{pp}$, or near the Lueneburg-North motorway access road at $11.7 \mathrm{pp}$ (except for the influence of the federal road, secured with the least possible probability of errors). A station on the commuter route to Gellersen (3.3 pp), on the route to Uelzen by $11.4 \mathrm{pp}$, has a positive effect on the probability of decreasing prices. Being a station on the commuter route Lueneburg-North is not significant. With regard to the location of the petrol stations, the picture is mixed. It is not surprising that a change to the surrounding area or a settlement in the immediate vicinity of adjacent petrol stations reduces the probability; the same applies to the location on the federal road or motorway. Being located on commuter routes increases sometimes the probability of lowering prices. The significant marginal average effects are economically quite remarkable.

If the evaluation concentrates on services offered by the petrol stations, Table 14 shows the probability of a price reduction event. The longer a petrol station is open, the more service offers could play a role, and for petrol stations located outside the city area, the less services should be important. For opening hours and rural areas, additional checks are therefore made in the estimate. Factors that significantly increase the probability of price reductions are petrol stations that have a shop by $3.2 \mathrm{pp}$, with a REWE-to-Go-Shop $2.2 \mathrm{pp}$, with toilets $0.9 \mathrm{pp}$, that accepts all credit cards $1.6 \mathrm{pp}$, with a car wash $3.3 \mathrm{pp}$, with a bistro $1.6 \mathrm{pp}$, with the offer of vacuum cleaners $3.1 \mathrm{pp}$. Significant negative influence to become an initiator for a price reduction event occurs when the property of a petrol station operates as a self-service station (2.6 pp). Automatic filling stations and filling stations with an in-house bakery have a highly significant $2.6 \mathrm{pp}$ and $5.4 \mathrm{pp}$ lower sink probabilities. Without significant impact are petrol stations with a car repair shop, ATMs, and higher consumer satisfaction. One hour longer opening hours on Saturdays, Sundays, and holidays significantly increase the probability of 
Table 14 Fixed-effect-logitservices, opening hours, and non-Lueneburg stations
Services

Car repair?

0.040

$|0.005|$

(0.55)

Self service station?

$-0.216^{* * *}$

$|-0.026|$

(0.054)

Station with shop?

$0.265^{* * *}$

$|0.032|$

(0.065)

Station with Rewe-to-Go-Shop?

$0.183^{*}$

$|0.022|$

(0.079)

ATM?

$-0.061$

$|-0.007|$

(0.043)

Restrooms available?

$0.077^{*}$

$|0.009|$

(0.035)

Number of accepted credit cards?

$0.136^{* * *}$

$|0.016|$

(0.016)

Car wash?

$0.277^{* * * *}$

$10.033 \mid$

(0.058)

Consumer satisfaction?

$-0.170$

$|-0.020|$

(0.105)

Bistro?

$0.135^{* * * *}$

$|0.016|$

(0.036)

$0.229^{* * *}$

|0.027|

(0.031)

$-0.452^{* * *}$

$|-0.054|$

(0.045)

Opening hours

Monday to Friday?

$-0.284^{* * *}$

$|-0.034|$

$(-11.22)$

$0.129^{* * * *}$

$|0.015|$

(0.025)

$0.065^{* * *}$

$10.008 \mid$

(0.008)

Stations in rural area? 
Table 14 (continued)

\begin{tabular}{ll}
\hline Services & \\
\hline LR-Test $X^{2}$ & 2364.85 \\
$(p$ value $)$ & $(0.000)$ \\
Observations & 260,141 \\
Groups & 10,627 \\
\hline
\end{tabular}

Dependent variable: within one round: $1=$ decreasing price observ., $0=$ non-decreasing price observ. Standard errors in parentheses; ${ }^{*} p<0.05,{ }^{* *} p<0.01,{ }^{* * *} p<0.001$. Variable "Kiosk" is omitted. Values in II marginal average effects. Own calculations by using Stata 16.0

reduction by 1.5 and $0.8 \mathrm{pp}$, respectively, whereas, on working days they decrease the probability by $3.4 \mathrm{pp}$. Filling stations located in rural areas have a small 0.5 percentage point reduction probability. Overall, the majority of service offerings have an increasing, but moderately positive influence on the willingness of a petrol station to leave paradise. Obviously, petrol stations with longer opening hours on working days often use the instrument of being the first to lower the price, perhaps to lure customers to their multi-offer business premises. The same could apply to petrol stations with longer opening hours on Saturdays and Sundays. Surprisingly, the opposite applies to longer opening hours on working days. However, it has to be said that there is no variation in the range of services or opening hours in the 2-year data set, as these cannot be reliably measured and may not have been relevant at all; this places limits on the interpretation of the fixed-effect logistic approach used.

Table 15 Fixed-effect-logit-price differences

\begin{tabular}{lll}
\hline & $(1)$ & $(2)$ \\
\hline Distance weighted price differences to nearest station, before & $-0.026^{* * *}$ & $0.039^{* * *}$ \\
& $|-0.005|$ & $(0.005 \mid$ \\
& $(0.06)$ & $(0.009)$ \\
Distance weighted price differences to second nearest station, before & 0.008 & $-0.021^{* * *}$ \\
& $|0.156|$ & $|-0.003|$ \\
Distance weighted price differences to third nearest station, before & $(0.005)$ & $(0.005)$ \\
& $0.070^{* * *}$ & $0.010^{*}$ \\
Price difference to price sinker, compared to price before & $|0.005|$ & $|0.002|$ \\
& $(0.016)$ & $(0.005)$ \\
Price difference $*$ duration; measured in machine h & & $0.184^{* * *}$ \\
& & $|0.042|$ \\
LR-Test X & & $(0.008)$ \\
(p values) & & $0.013^{* * *}$ \\
Observations & & $|0.003|$ \\
Groups & & $(0.002)$ \\
\hline
\end{tabular}

Dependent variable: within one round: $1=$ decreasing price observ., $0=$ non-decreasing price observ. Standard errors in parentheses; ${ }^{*} p<0.05,{ }^{* *} p<0.01,{ }^{* * *} p<0.001$. Values in $\|$ marginal average effects. Own calculations by using Stata 16.0 
Table 16 Fixed-effect-logit: price differences and station fixed-effects

(1)

Price difference to price sinker, compared to price before

$0.268^{\text {***: }}$

$10.067 \mid$

(0.010)

Price difference $*$ duration; measured in machine $\mathrm{h}$

$0.0109^{* * * *}$

$10.003 \mid$

(0.002)

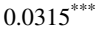

$10.008 \mid$

(0.005)

Distance weighted price differences to second nearest station, before

$-0.021^{* * *}$

$|-0.005|$

(0.006)

Distance weighted price differences to third nearest station, before

0.009

$10.002 \mid$

(0.005)

Stations, compared to Station 1

Station 2

$0.501 * * *$

$|0.125|$

(0.063)

Station 3

$0.269 * * *$

|0.067|

(0.065)

$0.282 * * *$

$|0.070|$

(0.063)

Station 5

$0.785^{* * *}$

$10.196 \mid$

(0.089)

Station 6

$1.081 * * *$

$|0.270|$

(0.065)

Station 7

$0.512 * * *$

$|0.0128|$

(0.067)

Station 8

$0.362 * * *$

|0.090|

(0.103)

Station 9

$0.514 * * *$

|0.128|

(0.064)

$1.455^{* * * *}$

$10.364 \mid$

(0.083)

$1.293 * * *$

$|0.323|$

(0.079)

$1.501 * * *$

$|0.375|$

(0.074) 
Table 16 (continued)

(1)

Station 13

$0.572 * * *$

$|0.143|$

(0.095)

Station 14

$1.316^{* * * *}$

$|0.329|$

(0.063)

Station 15

$-0.428 * * *$

|- $0.107 \mid$

(0.117)

Station 16

$0.736^{* * *}$

$|0.184|$

(0.063)

Station 17

$0.189 *$

|0.047|

(0.093)

Station 18

$0.633 * * *$

|0.158|

(0.091)

Station 19

$0.452 * * *$

$|0.113|$

(0.073)

Station 20

$0.596 * * *$

$|0.149|$

(0.099)

Station 21

$0.920 * * *$

$|0.230|$

(0.072)

Station 22

$1.467 * * *$

$10.367 \mid$

(0.063)

Station 23

$1.110 * * *$

|0.277|

(0.082)

Station 24

$0.583 * * *$

$|0.146|$

(0.067)

$0.832 * * *$

$10.208 \mid$

(0.094)

Station 26

$0.469 * * *$

$|0.117|$

(0.113)

7806.48

(0.000)

LR-Test $\mathrm{X}^{2}$

293,798

Observations

11,375

Groups

Dependent variable: within one round: $1=$ decreasing price observ., $0=$ non-decreasing price observ. Standard errors in parentheses; $* p<0.05, * * p<0.01$, *** ${ }^{*} p<0.001$. Values in II marginal average effects. Own calculations by using Stata 16.0 
In extension to Table 13, model 1 , the estimates in Table 15 concentrate on the price differences to competitors, i.e., the extent to which price pressure could explain directly, time-weighted or distance-dependent why a petrol station starts to reduce prices after previously rising prices. According to the first model, the average marginal effects for price differences to nearby petrol stations show hardly any economically relevant effects. In one case, it even showed an insignificant coefficient. One ct lower average price of the nearest petrol station lowers the probability of a price reduction event by $0.5 \mathrm{pp}$. The third nearest one increases it by the same pp value. If the estimate is extended by the average price difference and by time-weighted price differences, the price difference of the nearest station becomes highly significantly positive. The difference to the third nearest station, although still positive, is only hedged at the $5 \%$ level. In both cases, the marginal effects are economically very small ( $0.5 \mathrm{pp}$ each). In the price differences to the second closest provider, there is a significantly negative, but even smaller economic effect $(0.3 \mathrm{pp})$. Even the extended inclusion of price differences does not seem to have a major impact on the incentive to be the first to lower the price. In other words, price pressure as an explanatory variable has so far been ruled out, at least, rather, according to the estimation methods used.

Combining the various "structural" explanatory approaches, such as the importance of the two major petrol brands or the non-oligopolists, location factors, or service offerings with price pressure variables, results in Table 25 in the Appendix. As mentioned earlier, an estimation in which all explanatory variables are included simultaneously cannot be implemented due to lack of invertibility of the coefficient matrix. Model 1 combines the market structural variables with those of the location of the petrol stations included. Essentially, the same results are obtained for the location in terms of significance and marginal average effects. However, the marginal effects are reversed for the petrol station located directly next to the Lüneburg-Nord motorway access road. That location now has a 4 pp higher probability of decreasing price, secured at the 1/1000 level. Also, longer opening hours on Saturday reduce its probability of being the first to lower the price, although this effect is economically very small $(0.9 \mathrm{pp})$. Probably far more significant is that the market structural variables (Aral, Shell, national and local non-oligopolists) "keep" their signs but become considerably smaller. They reach just under $10 \mathrm{pp}$ or lower. Service offerings and the location of petrol stations seem to determine the probability of a reduction far more than under which brand/non-brand one offers one's services. The joint estimation of service variables with price differences (model 2) results in hardly any change in values compared to the above separate estimates, in particular, although price pressure as the theoretically most significant influence is still highly significant. From an economic perspective, the marginal average effects remain minimal. Model 3 combines price pressure variables with market structural factors. Now, only the market structural variables are subject to major changes. In three out of four cases, the marginal effects are now opposite. According to this model, Aral and Shell have lower probabilities of reductions and nationwide non-oligopolists have higher probabilities; however, all three variables remain below or just above the order of $5 \mathrm{pp}$ for the probabilities. Model 3 therefore feeds further doubts as to whether market structural factors actually play a major role in price reductions.

Finally, it can be examined whether price pressure variables explain the probabilities of reduction. If, in addition to the round-specific fixed effects, as assumed so far, station-specific effects also play a role. For this purpose, a dummy variable was created for each filling station and each filling station, with the exception of the Lueneburg 
Shell filling station in Universitaetsallee (\# 1), was included in the estimate. Table 16 shows the results; the petrol station results are always to be interpreted in comparison to the above petrol station (\# 1). The actual price pressure variables remain largely the same, both in their statistical validation and in their economic explanation. The average price differences of the competitors to the price of the sinker before its price reduction are time-weighted as well as distance-weighted. Prices of the nearest and the third nearest petrol stations increase the probability of a very significant reduction, but are only economically significant in the direct price difference (approx. $7 \mathrm{pp}$ ). All three others remain below 1 percentage point in difference. The second closest petrol station has a statistically lower probability of a reduction but is only limited to $0.6 \mathrm{pp}$. A look at the individual petrol stations reveals a differentiated picture. The stations bft, Lüneburg (\#12, 37.5 pp); Hoyer, Lueneburg (\#10, 36.4 pp); Shell, Kirchgellersen (\#22, 32.7 pp); Shell Lueneburg, Vor dem Bardowicker Tore (\#14, 32.9 pp); and HEM, Lüneburg (\#11, 32.3 pp) have particularly high, and of course highly significant, probabilities of decreasing prices. The Aral petrol station (Soltauer Allee, \# 3 , varied range of services) located near the center of Lueneburg and the independent petrol station Autohaus Plaschka are automatic petrol stations without any noteworthy service offerings (\# 15) and have a significantly lower probability of contributing to the price reduction, at 0.3 or considerable 10.7 percentage points. At the lower end of the increased reduction, probabilities are the stations Shell, Lueneburg, Erbstorfer Landstraße (\#7, 1.3 pp); Freie Tankstelle, Bardowick (\#17, 4.7 pp); Shell, Bardowick, Hamburger Landstraße (\#16, 6.3 pp); Aral, Lueneburg Dahlenburger Landstr. (\#4, $7 \mathrm{pp}$ ); and Star, Lueneburg, Auf den Bloecken (\#8, 9 pp). In total, the station-specific effects do not show a recognizable pattern. Neither is Shell always a price reducer, nor are the small independent suppliers to be regarded as "relative" non-sinkers. The same ambiguity exists in regard to the differentiation between city and rural petrol stations and the differences in service offerings. Only one thing becomes clear: station differences are far more influential than price pressure variables.

In summary, although the explanatory variables included usually produce highly significant coefficients, the results are not always as good as expected from an economic point of view. However, the economic explanatory contribution often produces only minor or even negligible marginal effects. This applies in particular to the variables that measure the price pressure for the price reducer, even though it is precisely from a theoretical point of view that price pressure should be the central explanatory factor. Market structural factors alone have a very high economic significance. When service variables, location parameters, and price differences are included, however, market structures dramatically lose in economic relevance. Service variables and location parameters are not methodologically well established, since in the data set service stations have neither changed their service offerings nor changed their location. Therefore, if one chooses to add "stationspecific" effects to the estimation model, the price pressure variables continue to stand out with extremely little economic relevance. The individual stations participate to a very different extent in being the first price reducer when they offer other services. Neither petrol stations that are highly likely to be the first to lower their prices, nor stations that are less likely to lower their prices have a recognizable pattern when it comes to their features. They do not belong to major brands, do not have the characteristic of being a petrol station in the city of Lueneburg, do not have a large range of services, and do not possess certain location characteristics. The present data set only allows for the conclusion that it is not the price differences that are important, but rather the features of the stations that determine whether one leaves the price paradise. 


\section{Robustness Checks}

It is possible that the derived results are distorted by the data selection. Gas station Aral Brietlingen (\#21), as already mentioned, seems to follow an "unconventional" pricing policy in the morning. More generally, the first price reduction rounds on respective days could be distorted, as the operators orientate themselves more on the price level of the previous evening than on the prices of their competitors, who are already open that morning. As the later price reduction rounds occur much less frequently than the first ones, there may be different motives for price reductions. It is also conceivable that the assumed rationality of gas stations is exaggerated. Although the prices of competitors are relevant for the price reduction decision of a gas station, which can be easily determined by MTU, the speed of reaction is overestimated. Instead of allowing gas stations to react even to competitors' prices that changed a second ago, as has been the case up to now, it is possible to rule out very timely changes. As a result, it is possible to make alternative estimates by excluding price changes less than 6 or 12 min ago. These exclusions also take into account the fact that, formally, gas stations only have to notify MTU of price changes within $5 \mathrm{~min}$. Although the obligation to report seems to be predominantly electronic and thus without time delay, reliable information on the "how" is not available. Furthermore, the generated definition of the price reduction event "suffers" from the fact that in most cases only 1 or 2 ct price reductions are observed. Consequently, alternative price reduction measures can be used to redo the estimates.

Table 17 shows the results of the robustness checks developed from the above considerations. In all alternative estimates, only the respective price pressure variables were used as explanatory variables, since the price difference is at the center of the economic explanatory approach. Column 1 shows the results reported in the last chapter if only price difference variables are used. Thus, if we compare the results of the estimates without the first round on the respective day (round 0 , column 2), we find almost exactly the same marginal average effects. If we examine only the influence of price pressure at petrol stations in the city area, we can include only those price reduction events that are attributable to petrol stations in Lueneburg in the given data set. Thus, we must exclude non-Lueneburg petrol stations (column 3a), or limit the data set from the outset only to city petrol stations and calculate new price reduction events from this, and an alternative data set results (column 3b). With the exception of the absolute price difference variable, the marginal average effects are the same in regard to

Table 17 Robustness check 1: fixed-effect-logit

\begin{tabular}{|c|c|c|c|c|c|c|c|c|c|c|c|}
\hline & \multirow{2}{*}{$\begin{array}{c}\text { (1) } \\
\text { All announ- } \\
\text { cements } \\
\text { (reference } \\
\text { Estimation) }\end{array}$} & \multirow{2}{*}{$\begin{array}{c}(2) \\
\text { Without } \\
\text { round } 0\end{array}$} & \multicolumn{2}{|c|}{$\begin{array}{cc}(3 \mathrm{a}) & (3 \mathrm{~b}) \\
\text { Lueneburg only }\end{array}$} & \multirow{2}{*}{$\begin{array}{c}\text { (4) } \\
\text { First ten } \\
\text { rounds } \\
\text { only }\end{array}$} & \multicolumn{2}{|c|}{$\begin{array}{lc}(5 \mathrm{a}) & (5 \mathrm{~b}) \\
\text { Without station } 21\end{array}$} & \multirow[b]{2}{*}{$\begin{array}{c}6) \\
\text { Without } \\
\text { latest 6 } \\
\text { minutes }\end{array}$} & \multirow{2}{*}{$\begin{array}{c}7) \\
\text { Without } \\
\text { latest } 12 \\
\text { minutes }\end{array}$} & \multirow{2}{*}{$\begin{array}{c}(8) \\
\text { Two cent } \\
\text { price } \\
\text { decreases } \\
\text { only } \\
\end{array}$} & \multirow[b]{2}{*}{$\begin{array}{c}9) \\
\text { One cent } \\
\text { price } \\
\text { decreases } \\
\text { only } \\
\end{array}$} \\
\hline & & & $\begin{array}{l}\text { Luene } \\
\text { Given } \\
\text { price } \\
\text { rounds }\end{array}$ & $\begin{array}{l}\text { Ne only } \\
\text { New } \\
\text { price } \\
\text { rounds }\end{array}$ & & $\begin{array}{l}\text { Withou } \\
\text { Given } \\
\text { price } \\
\text { rounds }\end{array}$ & $\begin{array}{l}\text { tation } 21 \\
\text { New } \\
\text { price } \\
\text { rounds }\end{array}$ & & & & \\
\hline & 0.184 & $0.184^{\circ}$ & $-0.222^{\circ *}$ & $-0.189^{\prime \prime \prime}$ & $0.192^{\circ}$ & $0.135^{\circ "}$ & $0.141^{\prime \prime \prime}$ & $0.247^{\prime \cdots}$ & $0.281^{\circ}$ & $0.177^{m}$ & $0.160^{\circ}$ \\
\hline $\begin{array}{l}\text { Price difterence to price } s \text { i } \\
\text { compared to price before }\end{array}$ & $\begin{array}{l}|0.043| \\
(0.008)\end{array}$ & $\begin{array}{l}|0.042| \\
(0.008)\end{array}$ & $\begin{array}{r}|-0.49| \\
(0.019)\end{array}$ & $\begin{array}{r}|-0.040| \\
(0.018)\end{array}$ & $\begin{array}{l}|0.044| \\
(0.009)\end{array}$ & $\begin{array}{l}|0.031| \\
(0.008)\end{array}$ & $\begin{array}{l}|0.032| \\
(0.008)\end{array}$ & $\begin{array}{l}|0.054| \\
(0.008)\end{array}$ & $\begin{array}{l}|0.059| \\
(0.008)\end{array}$ & $\begin{array}{l}|0.041| \\
(0.016)\end{array}$ & $\begin{array}{l}|0.038| \\
(0.010)\end{array}$ \\
\hline $\begin{array}{l}\text { Price difference * duration; } \\
\text { measured in machine h }\end{array}$ & $\begin{array}{c}0.0134 \\
|0.003| \\
(0.002)\end{array}$ & $\begin{array}{l}0.014 \\
|0.003| \\
(0.002)\end{array}$ & $\begin{array}{l}0.022 * \\
|0.005| \\
(0.003)\end{array}$ & $\begin{array}{l}0.025^{* *} \\
|0.005| \\
(0.001)\end{array}$ & $\begin{array}{l}0.013 \\
|0.003| \\
(0.002)\end{array}$ & $\begin{array}{l}0.022^{2 *} \\
|0.005| \\
(0.002)\end{array}$ & $\begin{array}{l}0.022^{* *} \\
|0.005| \\
(0.002)\end{array}$ & $\begin{array}{l}0.005^{4 *} \\
|0.001| \\
(0.001)\end{array}$ & $\begin{array}{c}-0.003 \\
|-0.0005| \\
(0.001)\end{array}$ & $\begin{array}{c}0.0160^{\circ * *} \\
|0.004| \\
(0.004)\end{array}$ & $\begin{array}{l}0.014^{* *} \\
|0.003| \\
(0.002)\end{array}$ \\
\hline Distance weighted price & $0.039^{* * *}$ & $0.036^{* *}$ & $0.314^{* * *}$ & $0.269^{* * *}$ & $0.042^{* *}$ & $0.031^{* *}$ & $0.031^{* *+4}$ & $0.043^{* *}$ & $0.040^{* * 4}$ & $0.0465^{\circ *}$ & $0.036^{* *}$ \\
\hline $\begin{array}{l}\text { differences to nearest station, } \\
\text { before }\end{array}$ & $\begin{array}{l}|0.008| \\
(0.004)\end{array}$ & $\begin{array}{l}|0.008| \\
(0.004)\end{array}$ & $\begin{array}{l}|0.070| \\
(0.013)\end{array}$ & $\begin{array}{l}|0.057| \\
(0.013)\end{array}$ & $\begin{array}{l}|0.010| \\
(0.005)\end{array}$ & $\begin{array}{l}|0.007| \\
(0.004)\end{array}$ & $\begin{array}{l}|0.007| \\
(0.004)\end{array}$ & $\begin{array}{l}|0.009| \\
(0.004)\end{array}$ & $\begin{array}{l}|0.008| \\
(0.005)\end{array}$ & $\begin{array}{l}|0.011| \\
(0.009)\end{array}$ & $\begin{array}{l}|0.009| \\
(0.006)\end{array}$ \\
\hline Distance weighted price & $-0.021^{* \ldots}$ & $-0.020^{* * *}$ & $-0.133^{* 2 *}$ & $-0.107^{* *}$ & $-0.015^{4}$ & $-0.023^{* * *}$ & $-0.021^{* *}$ & $-0.019^{* *}$ & $-0.014^{* *}$ & $-0.033^{4 *}$ & $-0.016^{\circ}$ \\
\hline differences to second nearest & $|-0.005|$ & $|-0.005|$ & $|-0.030|$ & $|-0.029|$ & $|-0.004|$ & $|-0.005|$ & $|-0.005|$ & $|-0.004|$ & $|-0.003|$ & $|-0.008|$ & $|-0.004|$ \\
\hline station, befor & $(0.005)$ & $(0.00$ & $(0.007-7$ & $(0.007)$ & $(0.006)$ & $(0.005)$ & $(0.005)$ & $(0.005)$ & $(0.005)$ & $(0.011)$ & $(0.007)$ \\
\hline Distance weighted price & $0.010^{7}$ & $0.011^{\circ}$ & $0.173^{.2}$ & $0.148^{* 4 *}$ & -0.001 & $0.028^{-2}$ & $0.026^{* 2 *}$ & $0.010^{2}$ & 0.008 & $0.024^{7}$ & 0.002 \\
\hline $\begin{array}{l}\text { differences to third nearest } \\
\text { station, before }\end{array}$ & $\begin{array}{l}|0.002| \\
(0.005)\end{array}$ & $\begin{array}{l}|0.003| \\
(0.005)\end{array}$ & $\begin{array}{l}|0.047| \\
(0.039)\end{array}$ & $\begin{array}{l}|0.031| \\
(0.008)\end{array}$ & $\begin{array}{r}|-0.001| \\
(0.005)\end{array}$ & $\begin{array}{l}|0.047| \\
(0.006)\end{array}$ & $\begin{array}{l}|0.048| \\
(0.006)\end{array}$ & $\begin{array}{l}|0.002| \\
(0.005)\end{array}$ & $\begin{array}{l}|0.002| \\
(0.005)\end{array}$ & $\begin{array}{l}|0.005| \\
(0.011)\end{array}$ & $\begin{array}{l}|0.001| \\
(0.007)\end{array}$ \\
\hline $\begin{array}{l}\text { LR-Test } \mathrm{X}^{2} \\
\text { (p values) }\end{array}$ & $\begin{array}{l}5,989.54 \\
(0.000)\end{array}$ & $\begin{array}{c}5,642.65 \\
(0.000)\end{array}$ & $\begin{array}{c}3,816,58 \\
(0.000)\end{array}$ & $\begin{array}{l}4,662,56 \\
(0.000)\end{array}$ & $\begin{array}{l}3,872,08 \\
(0.000)\end{array}$ & $\begin{array}{c}5,844,56 \\
(0.000)\end{array}$ & $\begin{array}{c}6,190.93 \\
(0.000)\end{array}$ & $\begin{array}{c}8,426.69 \\
(0.000)\end{array}$ & $\begin{array}{c}9,213.48 \\
(0.000)\end{array}$ & $\begin{array}{c}1,588.43 \\
(0.000)\end{array}$ & $\begin{array}{c}2,155.02 \\
(0.000)\end{array}$ \\
\hline Observations & 293,798 & 275,048 & 112,320 & 122,442 & 179,312 & 277,512 & 284,000 & 263,225 & 237,854 & 80,729 & 132,469 \\
\hline Groups & 11,375 & 10,647 & 7,171 & 7,805 & 6,949 & 10,904 & 11,162 & 11,375 & 11,375 & 3,128 & 5,121 \\
\hline
\end{tabular}

Dependent variable: within one round: $1=$ decreasing price observ., $0=$ non-decreasing price observ. Standard errors in parentheses; ${ }^{*} p<0.05,{ }^{* *} p<0.01,{ }^{* * *} p<0.001$. Values in $\|$ marginal average effects. Own calculations by using Stata 6.0 
the significance of the coefficients. With the absolute price difference, however, a fundamentally different result is obtained. With an increasing price difference of $1 \mathrm{ct}$, the probability of being the first to lower the price decreases by 4.9 or $4 \mathrm{pp}$. Although this approach reduces the number of cases to almost a third, the significant levels do not deteriorate at all. In this respect, it can only be stated that the result for petrol stations in the Lueneburg city area is counterintuitive if the absolute price difference is taken as a basis. However, all other price pressure variables do not change. If we estimate for the first ten price rounds only, there are almost no differences to the reference estimation (column 4). The omission of station \#21 (Aral, Brietlingen), which can be done by omitting the price reduction events of station 21 (column 5a) or by excluding the gas station at the beginning of the data set creation/formation of a new data set (column 5b), only leads to about 1 pp less effect on the absolute price difference compared to the reference situation, without a change in sign. If very short-term price reductions are excluded (6 min for column 6, and 12 min for column 7), almost everything also remains the same. Only the direct price difference leads to a $1 \mathrm{ct}$ higher average price, which in turn leads to a $1 \mathrm{pp}$ higher probability of a reduction compared to column 1 . If only the 1 or 2 ct reductions are taken into account, the marginal average effect for the direct price difference decreases slightly. Across all the robustness checks carried out, the results hardly differ; only the direct price difference when restricted to city petrol stations comes to a completely different, theoretically unexplainable result.

In further robustness checks, the price pressure variables for different fuel types (diesel, Super E5 and E10) were used. Since the data set is not reduced in scope (no price observations or petrol stations were excluded), it is possible to check for effects specific to petrol stations. Table 18, with the exclusively printed price pressure effects, shows that there are identical marginal average effects compared to the estimate in Table 16, shown in column 1. In this respect, the incentives to be the first to lower the price do not seem to differ with respect to the fuels offered.

The fact that the later observable willingness to be the first to lower the price, after which prices have previously gone up, would have feedback effects on the previously set prices can hardly be justified in theory (no problem of reverse causality). Whether the price differences determined are actually causal in the sense that the price cutters "respond" to them is first tested by (a) ruling out very short-term price cuts (less than 6 or $12 \mathrm{~min}$ ), (b) excluding the first round, and (c) only the first ten rounds. Secondly, checks were carried out for observable market structural factors (thus also for uniform group strategies at Aral and Shell), location factors, and service offerings, as well as for unobservable round-specific, and, if applicable, petrol station-specific fixed effects. The latter would, for example, also take into account the fact that individual petrol stations pursue a fixed price reduction policy, such as always reducing prices at the same time or always orienting themselves to a reference petrol station (if this is one of the three nearest petrol stations, this was explicitly controlled). Random price reduction behavior would be neglected by the approaches used. Of course, it is conceivable that other explanatory factors are relevant (omitted variables), but what should they be and how should they be measured? The alleged price pressure variables in particular explain only relatively little why price reductions occur.

\section{Summary and Conclusions}

German gas stations must report their current price reports to MTU of the Federal Cartel Office. Internet and app providers such as Clever Tanken use this information to generate information services that motorists can use to help them choose the cheapest filling 
Table 18 Robustness check 2

\begin{tabular}{|c|c|c|c|}
\hline & (1) & (2) & (3) \\
\hline & Diesel & E5 & E10 \\
\hline \multirow[t]{3}{*}{ Price difference to price sinker, compared to price before } & $0.268 * * *$ & $0.258 * * *$ & $0.247 * * *$ \\
\hline & $|0.067|$ & $|0.065|$ & $|0.062|$ \\
\hline & $(0.010)$ & $(0.010)$ & $(0.010)$ \\
\hline \multirow[t]{3}{*}{ Price difference $*$ duration; measured in machine $\mathrm{h}$} & $0.0109 * * *$ & $0.013 * * *$ & $0.009 * * *$ \\
\hline & $|0.003|$ & $|0.003|$ & $|0.002|$ \\
\hline & $(0.002)$ & $(0.002)$ & $(0.002)$ \\
\hline \multirow[t]{3}{*}{ Distance-weighted price differences to nearest station, before } & $0.0315 * * *$ & $0.023 * * *$ & $0.038 * * *$ \\
\hline & $|0.008|$ & $|0.006|$ & $|0.010|$ \\
\hline & $(0.005)$ & $(0.006)$ & $(0.005)$ \\
\hline \multirow[t]{3}{*}{ Distance-weighted price differences to second nearest station, before } & $-0.021 * * *$ & -0.005 & -0.007 \\
\hline & $|-0.005|$ & $|-0.001|$ & $|-0.002|$ \\
\hline & $(0.006)$ & $(0.006)$ & $(0.005)$ \\
\hline \multirow[t]{3}{*}{ Distance-weighted price differences to third nearest station, before } & 0.009 & 0.002 & -0.008 \\
\hline & $|0.002|$ & $|0.001|$ & $|-0.002|$ \\
\hline & $(0.005)$ & $(0.005)$ & $(0.005)$ \\
\hline LR-Test $\mathrm{X}^{2}$ & 7806.48 & 8187.11 & 8002.94 \\
\hline ( $p$ value) & $(0.000)$ & $(0.000)$ & $(0.000)$ \\
\hline Observations & 293,798 & 295,112 & 298,414 \\
\hline Groups & 11,375 & 11,461 & 11,577 \\
\hline
\end{tabular}

Dependent variable: within one round: $1=$ decreasing price observ., $0=$ non-decreasing price observ. Controlled for station dummies. Standard errors in parentheses; ${ }^{*} p<0.05$, $* * p<0.01, * * * p<0.001$. Values in II marginal average effects. Own calculations by using Stata 16.0

stations. Of course, this information is not only useful to those who demand it, but it is also much easier for providers to overlook the prices set by their local competitors than was the case before MTU was introduced at the end of 2013. In this respect, from an economic point of view, one would expect gas stations to react very quickly to price changes.

Gasoline prices in Germany fluctuate very strongly within a day. With a more or less fixed ritual, they go up in the late evening or in the middle of the night, drop relatively sharply in the early morning, and then go up and down again in the course of the day. In this paper, the price reduction of the supplier was identified for the Lueneburg area, who, after rising prices, is the first supplier to go down again. In economic terms, he is thus leaving the high price level for all petrol stations and lowering his price, although he should know from experience that his competitors will follow him. So, he is the first to give up the price paradise. According to the theory of Edgeworth cycles, such price undercutting occurs when the price-reducing petrol station (price reducer) is too expensive without a price reduction. Simply micro-economically speaking, one would lower one's price if the sales gains from the price reduction exceeded the sales losses that would not occur without the price reduction. Thus, especially petrol stations that compete on price due to worse locations tend to lower their price. In the same way, they would tend to lower prices if they wanted to attract customers by offering services. The existence of shops, for example, falls into this category. This quantity incentive is strengthened if, like the petrol stations tied to the big brands, they only receive a fixed revenue per quantity sold anyway. Suppliers with market power should have less need to act as the first price reducer. 
In order to explain who is the first to lower the price, the generally accessible data set has been massively revised. The data set I used, which covers the years 2018 and 2019 almost completely, was limited locally to the maximum of 26 petrol stations that are active in Lüneburg and the surrounding area. The limitation to one region allows the assumption that the companies located there are in competition with each other. On the basis of the definable first price reduction after price increases, the price that applied immediately before the price reduction event was determined for all petrol stations. The basic assumption of the essay was that one second before the price reduction event all petrol stations were facing the same price situation, but only one petrol station decided to reduce its price. The currently valid price observations of the non-lowerers, and those of the lowerers before their price reduction (26), plus the price observation of the lowerers with the reduced price form a panel unit. Up to 37 price reduction events on 1 day and thus panel observations could be identified. The reworking of the data in the manner described above thus allows the price dynamics to be mapped, which is extremely easy to identify due to the high time precision of MTU data. A fixed-effect logit approach was then used to test what distinguishes the price cutters from the non-price cutters.

For the estimated logit approaches, it is true that the explanatory variables included usually produce highly significant coefficients, but some of them produce only minor or quite limited significant effects from an economic point of view. According to the theory of Edgeworth cycles, the price pressure exerted by competitors should be particularly relevant for the price reducer, although it actually plays a relatively minor role. Market structural factors have a very high economic significance, which, however, is significantly reduced if service variables, location parameters, and price differences are included. Since service variables and location parameters do not change in the data set, an estimation model with "station-specific" effects is most plausible. There, the highly significant price pressure variables have only very little economic relevance. The factor alone, that on average $1 \mathrm{ct}$ cheaper competitors increase the probability of reduction by $6 \mathrm{pp}$, is economically significant. When looking at the station-specific effects, individual brands, service offerings, and certain location characteristics do not seem to be decisive. However, the stations themselves are more important than the price differences when it comes to willingness to leave the price paradise.

Sometimes it is Adam, and sometimes Eve, to leave the price paradise. One does not know why they do so. Is it not the external so-called seductive snake that pressures them to lower prices? These results are also robust for alternative model specifications. Only if the data set is reduced to petrol stations in urban areas do lower prices of competitors lead to a lower probability of lowering prices, a counterintuitive result.

The above results should be treated with caution to a certain extent. First, only the Lueneburg region was analyzed. In other regions, especially those with a different composition of the petrol station stock, the results could change. For the decisive question of market definition, however, local knowledge is extremely important in order to clearly define commuter routes, or to decide which fringe petrol stations still belong to them. It would also be nice to have variations over time in the market structure, services offered, and location variables. However, the effort required to record the service variables on a day-to-day basis is very high, and changes in brand image, or relocation are very rare in the German petrol station market. It should also be problematic that only price information is received before the price reduction event, but no one looks at what happens at least shortly afterwards. It is possible that other petrol stations react to the market situation with price reductions in the same way as the supplier reacts with the identified price reduction, perhaps only shortly afterwards. Considering how long the path is from the common evaluation of MTU 
data based on average prices at specific times, to the mapping of price dynamics as in this paper, should be left to further research. Overall, however, I fully agree with the thesis of Byrne and De Roos (2019) that the future of empirical research on gasoline prices will lie in the analysis of dynamic price processes.

\section{Appendix}

Table19

Table20

Table21

Table22

Table23

Table24

Table25

Table 19 Price announcements, 4 stations, 03/31/2019, premium gas E5

\begin{tabular}{|c|c|c|c|c|c|c|c|}
\hline \multicolumn{2}{|l|}{ Station 1} & \multicolumn{2}{|l|}{ Station 4} & \multicolumn{2}{|l|}{ Station 5} & \multicolumn{2}{|l|}{ Station 6} \\
\hline Time & Price in ct & Time & Price in ct & Time & Price in ct & Time & Price in ct \\
\hline 00:00:00 & 142.9 & 00:00:00 & 147.9 & $06: 35: 05$ & 143.9 & $06: 13: 05$ & 147.9 \\
\hline 06:00:08 & 152.9 & 08:19:05 & 137.9 & $08: 25: 05$ & 137.9 & $08: 14: 05$ & 138.9 \\
\hline 07:40:06 & 144.9 & 10:01:06 & 143.9 & $08: 31: 13$ & 136.9 & 08:47:09 & 137.9 \\
\hline 09:25:05 & 137.9 & $10: 34: 05$ & 142.9 & $10: 25: 05$ & 135.9 & $10: 22: 06$ & 136.9 \\
\hline 12:00:06 & 143.9 & 10:59:05 & 137.9 & $12: 51: 06$ & 139.9 & $12: 04: 06$ & 141.9 \\
\hline $13: 21: 07$ & 141.9 & 13:01:06 & 143.9 & $13: 29: 06$ & 138,9 & $13: 31: 12$ & 137,9 \\
\hline $13: 24: 06$ & 137.9 & $13: 51: 06$ & 139.9 & $13: 43: 06$ & 136.9 & $14: 51: 06$ & 136.9 \\
\hline 17:00:06 & 142.9 & 13:59:07 & 138,9 & $14: 45: 05$ & 135.9 & $17: 59: 05$ & 137,9 \\
\hline 17:52:06 & 137.9 & 14:19:05 & 137.9 & $17: 21: 06$ & 139.9 & $18: 47: 06$ & 136.9 \\
\hline 22:00:06 & 142.9 & 16:01:06 & 143.9 & $17: 59: 05$ & 138.9 & $22: 06: 06$ & 138.9 \\
\hline & & $16: 22: 06$ & 142.9 & 18:09:06 & 136.9 & & \\
\hline & & $16: 57: 05$ & 137.9 & $18: 59: 05$ & 135.9 & & \\
\hline & & 22:01:06 & 147.9 & & & & \\
\hline
\end{tabular}

1, Shell, Universitaetsalle; 4, Aral Dahlenburger Landstraße; 5, LTG Dahlenburger Landstraße; 6, Esso, Bleckeder Landstraße

Funding Open Access funding enabled and organized by Projekt DEAL. 
Table 20 Nearest stations

\begin{tabular}{|c|c|c|c|}
\hline Id & $\begin{array}{l}\text { Nearest station } \\
\text { id }\end{array}$ & Second nearest station & Third nearest station \\
\hline 1 & 2 & 3 & 13 \\
\hline 2 & 1 & 3 & 12 \\
\hline 3 & 12 & 11 & 2 \\
\hline 4 & 5 & 8 & 6 \\
\hline 5 & 4 & 6 & 8 \\
\hline 6 & 4 & 2 & 13 \\
\hline 7 & 13 & 4 & 19 \\
\hline 8 & 4 & 5 & 6 \\
\hline 9 & 10 & 15 & 13 \\
\hline 10 & 9 & 15 & 13 \\
\hline 11 & 3 & 13 & 14 \\
\hline 12 & 3 & 14 & 19 \\
\hline 13 & 14 & 15 & 7 \\
\hline 14 & 13 & 7 & 15 \\
\hline 15 & 1 & 9 & 13 \\
\hline 16 & 17 & 9 & 10 \\
\hline 17 & 16 & 9 & 10 \\
\hline 18 & 18 & 9 & 10 \\
\hline 19 & 18 & 7 & 9 \\
\hline 20 & 19 & 18 & 21 \\
\hline 21 & 18 & 19 & 17 \\
\hline 22 & 11 & 12 & 3 \\
\hline 23 & 4 & 5 & 26 \\
\hline 24 & 26 & 25 & 1 \\
\hline 25 & 1 & 2 & 24 \\
\hline 26 & 24 & 3 & 25 \\
\hline
\end{tabular}

Data Availability Data can be obtained on request. 


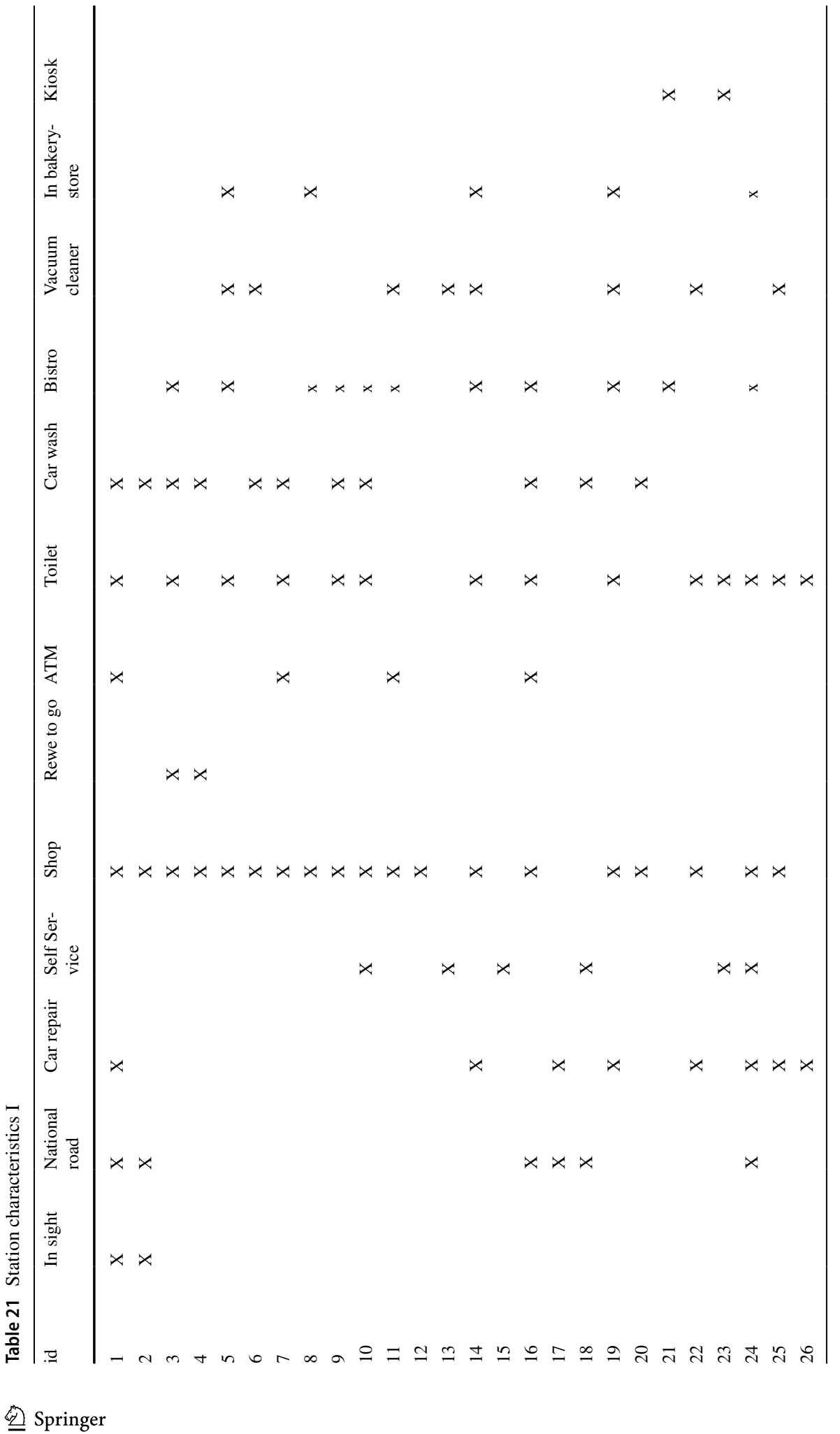


Table 22 Station characteristics II

\begin{tabular}{|c|c|c|c|c|c|c|c|c|}
\hline & $\begin{array}{l}\text { Dahlen- } \\
\text { burg }\end{array}$ & Gellersen & Uelezen & $\begin{array}{l}\text { Lüneburg- } \\
\text { Nord }\end{array}$ & $\begin{array}{l}\text { Lüneburg- } \\
\text { Mitte }\end{array}$ & Mo-Friday & Saturday & $\begin{array}{l}\text { Sunday/public- } \\
\text { holidays }\end{array}$ \\
\hline & Commut & r routes & & & & Opening ho & ours & \\
\hline 1 & & & $\mathrm{X}$ & $\mathrm{X}$ & & 24 & 24 & 24 \\
\hline 2 & & & $X$ & & & 17 & 16 & 15 \\
\hline 3 & & & & & & 24 & 24 & 24 \\
\hline 4 & $\mathrm{X}$ & & & & & 24 & 24 & 24 \\
\hline 5 & $\mathrm{X}$ & & & & & 16 & 15 & 14 \\
\hline 6 & & & & & & 18 & 16 & 16 \\
\hline 7 & & & & & $\mathrm{X}$ & 24 & 24 & 24 \\
\hline 8 & $\mathrm{X}$ & & & & & 17 & 17 & 14 \\
\hline 9 & & & & $\mathrm{X}$ & & 24 & 24 & 24 \\
\hline 10 & & & & & & 24 & 24 & 24 \\
\hline 11 & & $X$ & & & & 24 & 24 & 24 \\
\hline 12 & & $\mathrm{X}$ & & & & 16 & 15 & 14 \\
\hline 13 & & & & $\mathrm{X}$ & $\mathrm{X}$ & 24 & 24 & 24 \\
\hline 14 & & & & & & 18 & 17 & 16 \\
\hline 15 & & & & $\mathrm{X}$ & & 24 & 24 & 24 \\
\hline 16 & & & & & & 24 & 24 & 24 \\
\hline 17 & & & & & & 14.5 & 14 & 13 \\
\hline 18 & & & & & & 24 & 24 & 24 \\
\hline 19 & & & & & & 24 & 24 & 24 \\
\hline 20 & & & & & & 24 & 24 & 24 \\
\hline 21 & & & & & & 13 & 24 & 14 \\
\hline 22 & & $\mathrm{X}$ & & & & 16 & 16 & 14 \\
\hline 23 & $\mathrm{X}$ & & & & & 24 & 24 & 24 \\
\hline 24 & & & $\mathrm{X}$ & & & 17 & 16 & 24 \\
\hline 25 & & & & & & 24 & 24 & 24 \\
\hline 26 & & & & & & 12 & 6 & 0 \\
\hline
\end{tabular}


Table 23 Percentages of price decreasers per rounds, rounds 0-18

\begin{tabular}{|c|c|c|c|c|c|c|c|c|c|c|c|c|c|c|c|c|c|c|c|c|c|c|}
\hline \multirow[b]{2}{*}{ id } & \multirow[b]{2}{*}{$\begin{array}{l}\text { d } \\
\text { Brand } \\
\end{array}$} & \multirow{3}{*}{ Street } & \multirow[b]{2}{*}{ Place } & \multicolumn{19}{|c|}{ Round } \\
\hline & & & & 0 & 1 & 2 & 3 & 4 & 5 & 6 & 7 & 8 & 9 & 10 & 11 & 12 & 13 & 14 & 15 & 16 & 17 & 18 \\
\hline & & & \multirow{16}{*}{ Lueneburg } & & & & & & & & & & $\%$ & & & & & & & & & \\
\hline 1 & Shell & Universitätsallee 13 & & 2.5 & 5.8 & 4.3 & 3.2 & 4.6 & 3.8 & 3.4 & 3.3 & 3.8 & 2.9 & 2.7 & 3.6 & 4.0 & 2.2 & 2.8 & 5.0 & 2.5 & 2.4 & 3.7 \\
\hline 2 & \multirow{3}{*}{ ARAL } & Universitätsallee & & 3.9 & 8.5 & 8.4 & 8.0 & 6.1 & 5.6 & 5.4 & 4.0 & 4.4 & 5.6 & 7.1 & 5.2 & 3.7 & 5.8 & 5.3 & 6.6 & 7.7 & 5.2 & 8.2 \\
\hline 3 & & \begin{tabular}{|l} 
Soltauer Str. \\
\end{tabular} & & 3.4 & 5.0 & 6.3 & 6.5 & 5.3 & 4.6 & 5.9 & 6.6 & 4.1 & 5.1 & 5.8 & 5.2 & 6.8 & 6.0 & 4.4 & 4.1 & 10.5 & 9.2 & 6.9 \\
\hline 4 & & \begin{tabular}{|l} 
Dahlenburger Landstr. \\
.
\end{tabular} & & 5.0 & 6.7 & 9.9 & 7.7 & 7.6 & 8.4 & 8.0 & 7.2 & 8.2 & 8.1 & 8.6 & 8.0 & 9.2 & 8.2 & 6.6 & 5.9 & 4.9 & 6.4 & 5.0 \\
\hline 5 & LTG & Dahlebu & & 1.3 & 3.4 & 2.4 & 3.7 & 2.9 & 2.1 & 1.3 & 2.1 & 1.1 & 1.4 & 1.1 & 1.6 & 1.1 & 1.4 & 1.9 & 1.9 & 0.7 & 1.2 & 2.7 \\
\hline 6 & ESSO & Blecked & & 13.1 & 2.6 & 3.0 & 3.2 & 3.9 & 5.0 & 4.3 & 6.0 & 4.7 & 4.7 & 6.0 & 4.4 & 5.1 & 8.4 & 6.9 & 7.5 & 9.8 & 7.6 & 8.2 \\
\hline 7 & Shell & Erbstc & & 6.6 & 3.9 & 4.5 & 4.8 & 5.0 & 3.9 & 3.7 & 3.3 & 3.6 & 5.2 & 5.3 & 4.2 & 5.1 & 4.6 & 6.1 & 4.7 & 3.9 & 4.4 & 6.4 \\
\hline 8 & STAR & Auf den & & 1.1 & 2.6 & 1.1 & 1.7 & 0.7 & 0.4 & 0.9 & 1.5 & 0.6 & 0.8 & 0.9 & 1.2 & 1.1 & 0.7 & 0.8 & 0.3 & 0.7 & 1.2 & 0.5 \\
\hline 9 & ARAL & Hambur & & 5.4 & 6.6 & 6.3 & 5.2 & 6.5 & 7.1 & 4.6 & 5.3 & 5.7 & 4.6 & 5.5 & 7.0 & 6.2 & 6.2 & 6.4 & 8.8 & 7.4 & 6.0 & 6.4 \\
\hline 10 & Hoyer & Besser & & 3.2 & 5.2 & 4.4 & 4.4 & 3.0 & 2.7 & 3.4 & 1.1 & 2.5 & 2.0 & 2.7 & 2.6 & 2.4 & 1.4 & 3.3 & 2.5 & 1.1 & 2.0 & 3.7 \\
\hline 11 & HEM & Vor dem Neuen T & & 1.5 & 3.0 & 2.1 & 2.2 & 1.7 & 2.1 & 2.3 & 2.7 & 3.5 & 2.9 & 3.1 & 5.0 & 3.3 & 2.4 & 4.4 & 2.2 & 7.4 & 3.6 & 5.0 \\
\hline 12 & Bft & Am Grasweg 32 & & 2.8 & 2.6 & 2.8 & 2.8 & 3.9 & 3.5 & 3.0 & 4.5 & 4.7 & 3.5 & 5.1 & 4.4 & 6.8 & 6.5 & 6.1 & 7.5 & 7.4 & 7.2 & 6.85 \\
\hline 13 & $\begin{array}{l}\text { Beckmann/- } \\
\text { Lindemann }\end{array}$ & Auf der Hude & & 2.5 & 2.1 & 3.3 & 1.8 & 1.2 & 1.8 & 1.0 & 0.6 & 2.1 & 1.0 & 1.1 & 1.4 & 1.3 & 1.0 & 1.1 & 1.9 & 1.4 & 1.2 & 0.5 \\
\hline 14 & Shell & Vor dem Bardowicker To & & 1.1 & 4.0 & 4.5 & 4.1 & 7.3 & 8.7 & 8.3 & 10.2 & 10.4 & 10.3 & 8.6 & 11.2 & 6.8 & 9.4 & 9.9 & 10.0 & 4.6 & 10.8 & 6.4 \\
\hline 15 & \begin{tabular}{|l|} 
Freie \\
Tankstelle
\end{tabular} & Hamburger Str. & & 0.3 & 0.4 & 1.1 & 1.2 & 1.4 & 0.6 & 0.6 & 0.2 & 0.5 & 0.8 & 1.1 & 1.4 & 1.1 & 0.7 & 1.4 & 1.9 & 0.7 & 2.0 & 1.4 \\
\hline 16 & Shell & Hamburger Landstr. 20 & & 17.2 & 6.2 & 5.5 & 4.3 & 5.1 & 6.1 & 6.6 & 5.1 & 5.2 & 7.1 & 5.8 & 7.6 & 6.4 & 7.0 & 4.1 & 2.8 & 6.3 & 6.0 & 4.1 \\
\hline 17 & \begin{tabular}{|l|} 
Freie \\
Tankstelle \\
Salewski \\
\end{tabular} & Hamburger Landstr. & Bardowick & 2.8 & 2.6 & 2.3 & 1.8 & 1.4 & 1.1 & 1.3 & 0.8 & 2.7 & 1.9 & 1.5 & 0.8 & 0.9 & 2.0 & 0.6 & 0.6 & 1.1 & 1.2 & 1.8 \\
\hline 18 & JET & Artlent & & 2.6 & 4.0 & 2.2 & 2. & 1. & 1.8 & 0.4 & 1.1 & 0.6 & & 1.3 & 1.4 & 1.5 & & 0.8 & 6 & 1.4 & 1.2 & 0.9 \\
\hline 19 & Shell & Bueltenweg & dendorf & 1.4 & 1.9 & 2.5 & 5.4 & 2.8 & 6.6 & 5.4 & 3.6 & 6.2 & 4.4 & 4.2 & 4.2 & 3.7 & 1.7 & 1.9 & 1.6 & 1.4 & 1.2 & 0.9 \\
\hline 20 & Raiffeisen & Raiffeisenstr. & & 1.2 & 1.7 & 1.8 & 2.1 & 1.5 & 1.5 & 1.4 & 2.0 & 1.3 & 1.7 & 1.3 & 0.6 & 0.7 & 1.9 & 1.9 & 1.3 & 2.1 & 0.0 & 0.5 \\
\hline 21 & ARAL & Bundesstr. & ietlingen & 4.3 & 5.0 & 4.4 & 4.8 & 6.9 & 4.6 & 5.4 & 6.3 & 4.0 & 4.9 & 5.5 & 3.8 & 5.1 & 3.8 & 3.0 & 2.2 & 2.1 & 2.8 & 1.4 \\
\hline 22 & Shell & Lueneburger Str. & Kirch- & 3.2 & 7.3 & 6.2 & 8.1 & 8.7 & 8.0 & 10.4 & 11.3 & 9.9 & 10.9 & 7.9 & 4.8 & 9.5 & 7.9 & 8.8 & 9.7 & 6.0 & 6.4 & 9.1 \\
\hline 23 & Raiffeis & LL & & 2.6 & 3.2 & 4. & 4. & 2.6 & 1. & 2.4 & 3.5 & 2 & 1.4 & 0. & 1.8 & 1.5 & 1.9 & 2 & 2 & 1.8 & 2.0 & 0.9 \\
\hline 24 & Shell & Uelzener Str. & Melbeck & 10.2 & 3.7 & 3.6 & 2.9 & 4.8 & 4.3 & 6.0 & 5.4 & 4.7 & 5.9 & 4.4 & 5.8 & 5.3 & 6.2 & 6.9 & 5.3 & 4.9 & 4.8 & 7.3 \\
\hline 25 & LTG & Timelostr. & $\begin{array}{l}\text { Deutsch } \\
\text { Evern }\end{array}$ & 1.1 & 0.7 & 1.7 & 1.7 & 1.9 & 2.4 & 2.4 & 1.4 & 1.4 & 1.0 & 1.5 & 2.0 & 1.1 & 1.2 & 1.4 & 2.2 & 2.1 & 0.8 & 0.5 \\
\hline 26 & & Bahnhofstr. & Embsen & 0.3 & 1.5 & 1.4 & 1.8 & 1.2 & 1.5 & 2.0 & 0.6 & 1.7 & 0.5 & 1.3 & 0.6 & 0.4 & 0.0 & 0.8 & 0.9 & 0.4 & 3.2 & 0.9 \\
\hline Sum & $m$ of $p$ & easers & & 728 & 728 & 728 & 727 & 723 & 717 & 699 & 667 & 635 & 594 & 548 & \begin{tabular}{|l|}
499 \\
\end{tabular} & 455 & 417 & 362 & 320 & 285 & 250 & 219 \\
\hline
\end{tabular}

Table 24 Percentages of price decreasers per rounds, rounds 19-36

\begin{tabular}{|c|c|c|c|c|c|c|c|c|c|c|c|c|c|c|c|c|c|c|c|c|}
\hline \multirow[b]{2}{*}{ id } & \multirow[b]{2}{*}{ Brand } & \multirow[b]{2}{*}{ Street } & \multirow[b]{2}{*}{ Place } & \multicolumn{17}{|c|}{ Round } \\
\hline & & & & 19 & 20 & 21 & 23 & 24 & \begin{tabular}{|l|}
25 \\
\end{tabular} & 26 & 27 & 28 & 29 & 30 & 31 & 32 & 33 & 34 & 35 & 36 \\
\hline & & & & & & & & & & & & $\%$ & & & & & & & & \\
\hline 1 & Shell & Universitätsallee 13 & \multirow{15}{*}{ Lueneburg } & 5.7 & 2.4 & 3.4 & 2.9 & 5.1 & 3.2 & 6.1 & 2.6 & 10.0 & 4.6 & 0.0 & 6.3 & 25.0 & 0.0 & 0.0 & 0.0 & 0.0 \\
\hline 2 & \multirow{3}{*}{ ARAL } & Universitätsallee & & 7.3 & 6.7 & 4.2 & 7.8 & 5.1 & 3.2 & 8.2 & 15.4 & 6.7 & 4.6 & 10.5 & 6.3 & 0.0 & 16.7 & 0.0 & 0.0 & 0.0 \\
\hline 3 & & Soltauer Str. & & 5.7 & 12.2 & 6.3 & 7.8 & 3.8 & 6.5 & 4.1 & 2.6 & 6.7 & 18.2 & 10.5 & 0.0 & 0.0 & 0.0 & 0.0 & 33.3 & 0.0 \\
\hline 4 & & \begin{tabular}{|l|} 
Dahlenburger Landstr. \\
.
\end{tabular} & & 3.6 & 4.9 & 5.6 & 7.8 & 10.1 & 3.2 & 12.2 & 0.0 & 6.7 & 13.6 & 0.0 & 12.5 & 0.0 & 0.0 & 0.0 & 0.0 & 0.0 \\
\hline 5 & LTG & Dahleburger Landstr. & & 1.6 & 1.8 & 1.4 & 0.0 & 0.0 & 4.8 & 0.0 & 5.1 & 3.3 & 0.0 & 10.5 & 6.3 & 0.0 & 16.7 & 0.0 & 0.0 & 0.0 \\
\hline 6 & ESSO & Bleckeder Landstr. 35 & & 11.4 & 11.6 & 11.3 & 14.6 & 16.5 & 4.8 & 12.2 & 12.8 & 6.7 & 4.6 & 10.5 & 6.3 & 25.0 & 33.3 & 20.0 & 0.0 & 0.0 \\
\hline 7 & Shell & Erbstorfer Landstr. $2 \mathrm{~b}$ & & 3.1 & 5.5 & 5.6 & 1.0 & 2.5 & 3.2 & 2.0 & 5.1 & 3.3 & 4.6 & 0.0 & 18.8 & 25.0 & 0.0 & 0.0 & 0.0 & 0.0 \\
\hline 8 & STAR & Auf den Bloecken & & 3.1 & 3.1 & 1.4 & 1.0 & 0.0 & 3.2 & 0.0 & 7.7 & 3.3 & 9.1 & 5.3 & 6.3 & 0.0 & 0.0 & 20.0 & 0.0 & 0.0 \\
\hline 9 & ARAL & Hamburger Str. & & 6.7 & 5.5 & 5.6 & 4.9 & 5.0 & 4.8 & 6.1 & 10.3 & 13.3 & 9.1 & 5.3 & 12.5 & 0.0 & 16.7 & 0.0 & 0.0 & 100.0 \\
\hline 10 & Hoyer & Bessemer Str & & 2.1 & 0.6 & 4.2 & 3.9 & 1.3 & 1.6 & 2.0 & 2.6 & 3.3 & 13.6 & 0.0 & 0.0 & 0.0 & 0.0 & 0.0 & 0.0 & 0.0 \\
\hline 11 & HEM & Vor dem Neuen Tore & & 4.7 & 6.1 & 6.3 & 1.9 & 10.1 & 3.2 & 4.1 & 10.3 & 3.3 & 4.6 & 5.3 & 0.0 & 0.0 & 0.0 & 0.0 & 33.3 & 0.0 \\
\hline 12 & Bft & Am Gra & & 6.2 & 5.5 & 7.8 & 3.9 & 7.6 & 8.1 & 8.2 & 2.6 & 6.7 & 0.0 & 0.0 & 6.3 & 0.0 & 0.0 & 0.0 & 0.0 & 0.0 \\
\hline 13 & Beckmann/Lindemann & Auf der Hude & & 1.6 & 0.6 & 2.8 & 0.0 & 0.0 & 0.0 & 2.0 & 0.0 & 0.0 & 0.0 & 0.0 & 0.0 & 0.0 & 0.0 & 0.0 & 0.0 & 0.0 \\
\hline 14 & Shell & Vor dem Bardowicker Tore & & 7.3 & 7.3 & 8.5 & 10.7 & 8.9 & 6.5 & 4.1 & 10.3 & 3.3 & 0.0 & 0.0 & 0.0 & 25.0 & 0.0 & 0.0 & 0.0 & 0.0 \\
\hline 15 & Freie Tankstelle & Hambu & & 0.5 & 1.8 & 0.0 & 0.0 & 0.0 & 1.6 & 0.0 & 0.0 & 0.0 & 4.6 & 0.0 & 0.0 & 0.0 & 0.0 & 0.0 & 33.3 & 0.0 \\
\hline 16 & Shell & Hamburger Landstr. 20 & \multirow{2}{*}{ Bardowick } & 6.8 & 4.3 & 7.0 & 1.0 & 5.1 & 9.7 & 8.2 & 2.6 & 6.7 & 0.0 & 21.1 & 0.0 & 0.0 & 0.0 & 40.0 & 0.0 & 0.0 \\
\hline 17 & Freie Tankstelle Salewski & Hamburger Landstr. & & 0.5 & 3.1 & 0.0 & 1.9 & 0.0 & 1.6 & 0.0 & 0.0 & 0.0 & 0.0 & 0.0 & 0.0 & 0.0 & 0.0 & 0.0 & 0.0 & 0.0 \\
\hline 18 & JET & Artlenburger Landstr. 62 & \multirow[b]{2}{*}{ Adendorf } & 1.0 & 1.2 & 1.4 & 3.9 & 5.1 & 4.8 & 4.1 & 0.0 & 3.3 & 0.0 & 0.0 & 0.0 & 0.0 & 0.0 & 0.0 & 0.0 & 0.0 \\
\hline 19 & Shell & Bueltenweg & & 1.6 & 0.0 & 0.0 & 2.9 & 1.3 & 3.2 & 2.0 & 2.6 & 0.0 & 0.0 & 5.3 & 0.0 & 0.0 & 0.0 & 0.0 & 0.0 & 0.0 \\
\hline 20 & Raiffeisen & Raiffeisenstr. & Scharnebeck & 3.6 & 0.0 & 0.0 & 0.0 & 0.0 & 1.6 & 2.0 & 0.0 & 3.3 & 0.0 & 0.0 & 0.0 & 0.0 & 0.0 & 0.0 & 0.0 & 0.0 \\
\hline 21 & ARAL & Bundesstr. & Brietlingen & 0.5 & 1.2 & 0.0 & 0.0 & 0.0 & 0.0 & 0.0 & - & - & - & - & - & - & - & - & - & - \\
\hline 22 & Shell & Lueneburger Str. & \begin{tabular}{|l} 
Kirch- \\
gellersen
\end{tabular} & 3.6 & 4.9 & 5.6 & 8.7 & 3.8 & 4.8 & 6.1 & 0.0 & 0.0 & 4.6 & 0.0 & 6.3 & 0.0 & 0.0 & 0.0 & 0.0 & 0.0 \\
\hline 23 & Raiffeisen & Lueneburger Str. & Barendorf & 2.1 & 1.2 & 0.7 & 1.9 & 2.5 & 1.6 & 0.0 & 0.0 & 0.0 & 0.0 & 0.0 & 0.0 & 0.0 & 0.0 & 0.0 & 0.0 & 0.0 \\
\hline 24 & Shell & Uelzener Str. & Melbeck & 7.8 & 6.1 & 8.5 & 6.8 & 3.8 & 12.9 & 4.1 & 2.6 & 0.0 & 0.0 & 10.5 & 0.0 & 0.0 & 0.0 & 0.0 & 0.0 & 0.0 \\
\hline 25 & \multirow[t]{2}{*}{ LTG } & Tim & \begin{tabular}{|l} 
Deutsch \\
Evern \\
\end{tabular} & 2.1 & 1.2 & 1.4 & 3.9 & 1.3 & 1.6 & 0.0 & 5.1 & 6.7 & 4.6 & 5.3 & 6.3 & 0.0 & 0.0 & 0.0 & 0.0 & 0.0 \\
\hline 26 & & Bahnhofstr. & Embsen & 0.0 & 1.2 & 0.7 & 1.0 & 1.3 & 0.0 & 2.0 & 0 & 0.0 & 0.0 & 0.0 & 6.3 & 0.0 & 0.0 & 0.0 & 0.0 & 0.0 \\
\hline Su & & & & 193 & 164 & 142 & 103 & 19 & 62 & 49 & 39 & 30 & 22 & 19 & 16 & 8 & & & 3 & \\
\hline
\end{tabular}


Table 25 Fixed-effect-logit 4

(1)

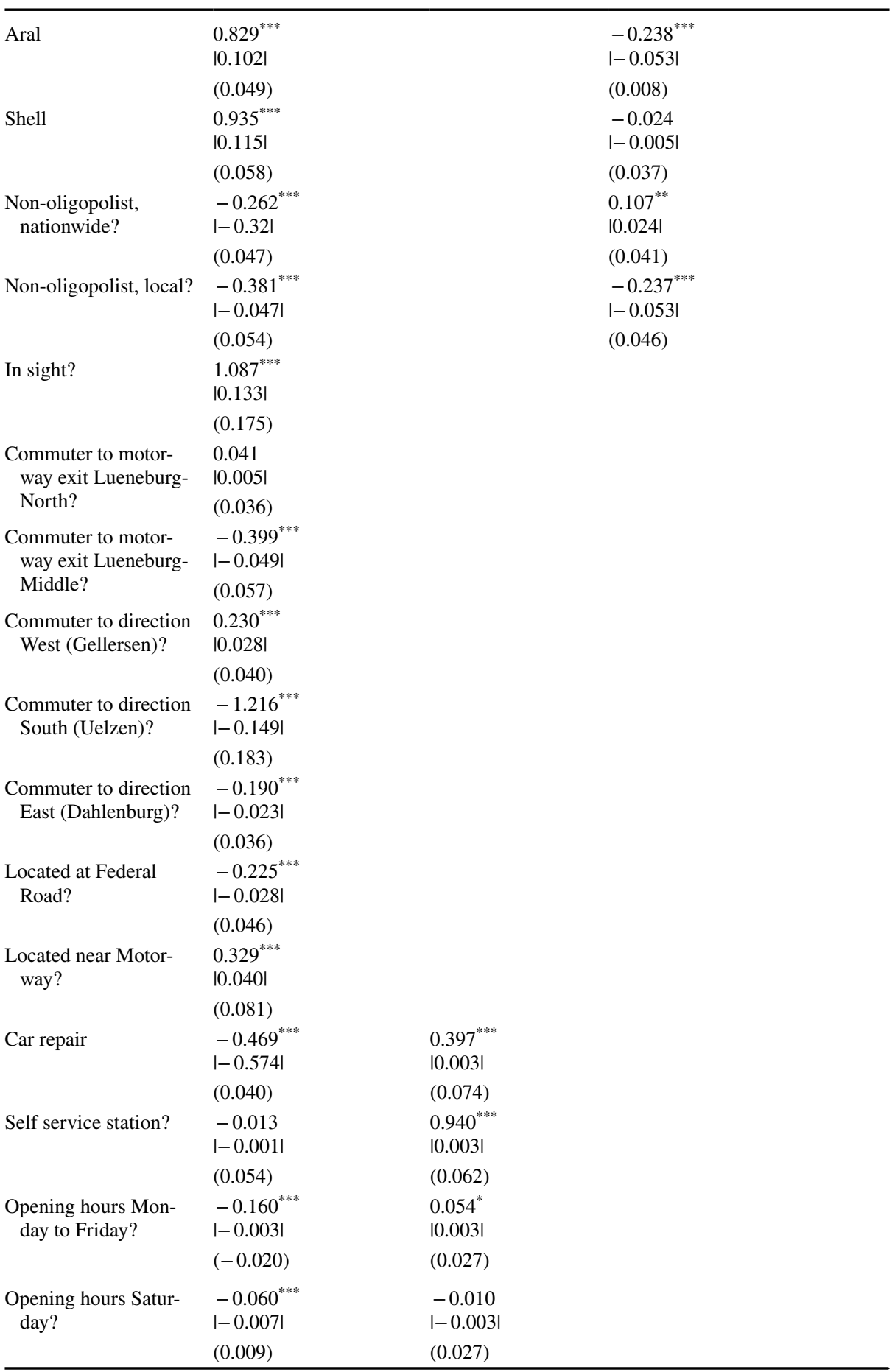

(2) (3)

$-0.238^{*}$

$-0.0531$

$-0.024$

$|-0.005|$

$-0.237^{* * *}$

(1)

0.054

$0.133 \mid$

$-0.149$

0.023

0.028

0.040

$(0.074)$

$40^{* * * *}$

$0.062)$

0.054

0.003

.003 
Table 25 (continued)

(1)

Opening hours Sunday/

Public Holiday?

$0.137^{*}$

$10.017 \mid$

(0.016)

Price difference to price sinker, compared to price before

Price difference * duration; measured in machine $h$

Distance weighted price differences to nearest station, before

Distance weighted price differences to second nearest station, before

Distance weighted price differences to third nearest station, before

Station with Shop?

Station with Rewe-toGo-Shop?

ATM?

Restrooms available?

Number of accepted credit cards?

Car Wash?

Consumer satisfaction?

Bistro?

Vacuum cleaner?
(2)

(3)

$-0.098^{* *}$

$|-0.003|$

(0.010)

$0.229^{* * * *}$

|0.021|

$0.202^{* * *}$

(0.010)

$|0.045|$

$0.017^{\text {**** }}$

(0.008)

$|0.002|$

$0.014^{\text {**** }}$

(0.002)

|0.003|

$0.029^{* * *}$

(0.002)

$|0.003|$

$0.039^{\text {*** }}$

(0.005)

|0.009|

(0.004)

$-0.032^{\text {**** }}$

$-0.025^{\text {*** }}$

$|-0.003|$

$|-0.006|$

(0.006)

(0.005)

$\begin{array}{ll}0.030^{* * *} & 0.014^{* *} \\ |0.003| & |0.003| \\ (0.005) & (0.005)\end{array}$

$1.463^{\text {*** }}$

$|0.133|$

(0.072)

$0.400^{* * * *}$

$10.036 \mid$

(0.079)

$0.288^{* * * *}$

|0.026|

(0.044)

$-0.148^{\text {**** }}$

$|-0.013|$

(0.037)

$-0.073^{\text {**** }}$

$|-0.007|$

(0.013)

$0.149^{*}$

|0.014|

(0.062)

$0.575^{\text {*** }}$

$|0.052|$

(0.106)

$0.371^{* * * *}$

|0.034|

(0.039)

$0.488^{* * * *}$

|0.044|

(0.034) 
Table 25 (continued)

(1)

In-store bakery?

Stations in rural area?

LR-Test X2

( $p$ value)

Observations

Groups
(2)

$-0.556^{\text {*** }}$

$|-0.051|$

(0.048)

$0.111^{\text {**** }} \quad 0.021$

$10.010 \mid$

$10.005 \mid$

(0.028)

(0.022)

6983.96

(0.000)

6143.82

(0.000)

260,141

293,798

10,627

11,375

Dependent variable: within one round: $1=$ decreasing price observ., $0=$ non-decreasing price observ. Standard errors in parentheses; ${ }^{*} p<0.05,{ }^{* *} p<0.01,{ }^{* * *} p<0.001$. Variable "round" has been omitted. Values in ॥ marginal average effects. Own calculations by using Stata 16.0

Code Availability Not applicable.

\section{Declarations}

Competing Interests The author declares no competing interests.

Open Access This article is licensed under a Creative Commons Attribution 4.0 International License, which permits use, sharing, adaptation, distribution and reproduction in any medium or format, as long as you give appropriate credit to the original author(s) and the source, provide a link to the Creative Commons licence, and indicate if changes were made. The images or other third party material in this article are included in the article's Creative Commons licence, unless indicated otherwise in a credit line to the material. If material is not included in the article's Creative Commons licence and your intended use is not permitted by statutory regulation or exceeds the permitted use, you will need to obtain permission directly from the copyright holder. To view a copy of this licence, visit http://creativecommons.org/licenses/by/4.0/.

\section{References}

ADAC (2019), Tankstellen in Deutschland, https:/www.adac.de/verkehr/tanken-kraftstoff-antrieb/deuts chland/tankstellen-in-deutschland/, used 02/17/2021.

Atkinson B (2009) Retail gasoline price cycles: evidence from Guelph, Ontario using bi-hourly, stationspecific retail price data. Energy J 30(1):85-109

Atkinson B, Eckert A, West DS (2014) Daily price cycles and constant margins: recent events in Canadian gasoline retailing. Energy J 35:47-69

Bacon RW (1991) Rockets and feathers: the asymmetric speed of adjustment of UK retail gasoline prices to cost changes. Energy Econ 13(3):211-218

Borenstein S, Shepard A (2002) Sticky prices, inventories, and market power in wholesale gasoline markets. RAND J Econ 33(1):116-139

Bremmer DS, Kesselring RG (2016) The relationship between US retail gasoline and crude oil prices during the Great Recession: "rockets and feathers" or "balloons and rocks" behavior? Energy Econ 55:200-210

Byrne DP, De Roos N (2017) Consumer search in retail gasoline markets. J Ind Econ 65(1):183-193

Byrne DP, De Roos N (2019) Learning to coordinate: a study in retail gasoline. Am Econ Rev 109(2):591-619

Byrne DP, Leslie GW, Ware R (2015) How do consumers respond to gasoline price cycles? Energy J 36:115-147 
Chandra A, Tappata M (2011) Consumer search and dynamic price dispersion: an application to gasoline markets. Rand J Econ 42(4):681-704

Deltas G (2008) Retail gasoline price dynamics and local market power. J Ind Econ 56(3):613-628

De Roos N, Katayama H (2013) Gasoline price cycles under discrete time pricing. Econ Rec 89(285):175-193

Dewenter R, Heimeshoff U, Lüth H (2017) The impact of the market transparency unit for fuels on gasoline prices in Germany. Appl Econ Lett 24(5):302-305

Doyle J, Muehlegger E, Samphantharak K (2010) Edgeworth cycles revisited. Energy Economics 32(3):651-660

Eibelshäuser S, Wilhelm S (2017) Markets take breaks: dynamic price competition with opening hours. J Econ. Surv 27(1):140-166

Foros $\varnothing$, Steen F (2013) Vertical control and price cycles in gasoline retailing. Scand J Econ 115(3):640-661

Galeotti M, Lanza A, Manera M (2003) Rockets and feathers revisited: an international comparison on European gasoline markets. Energy Econ 25(2):175-190

Haucap J, Heimeshoff U, Siekmann M (2017a) Fuel prices and station heterogeneity on retail gasoline markets. Energy J 38(6):81-103

Haucap J, Heimeshoff U, Kehder C, Odenkirchen J, Thorwarth S (2017b) Auswirkungen der Markttransparenzstelle für Kraftstoffe. Wirtschaftsdienst 97(10):721-726

Lewis MS (2012) Price leadership and coordination in retail gasoline markets with price cycles. Int J Ind Organ 30(4):342-351

Lewis M, Noel M (2011) The speed of gasoline price response in markets with and without Edgeworth cycles. Rev Econ Stat 93(2):672-682

Maskin E, Tirole J (1988) A theory of dynamic oligopoly, II: Price competition, kinked demand curves, and Edgeworth cycles. Econometrica 56:571-599

Neukirch A, Wein T (2019) Price Gouging at the Pump? The Lerner Index and the German Fuel Market. Rev Econ 70(2):157-192

Noel MD (2007a) Edgeworth price cycles: evidence from the Toronto retail gasoline market. J Ind Econ 55(1):69-92

Noel MD (2007b) Edgeworth price cycles, cost-based pricing, and sticky pricing in retail gasoline markets. Rev Econ Stat 89(2):324-334

Noel MD (2008) Edgeworth price cycles and focal prices: Computational dynamic Markov equilibria. JEMS 17(2):345-377

Nguyen M, Steen F (2018) Measuring market power in gasoline retailing: a market-or station phenomenon?. NHH Dept. of Economics Discussion Paper, (06).

Siekmann M (2017) Characteristics, causes, and price effects: Empirical evidence of intraday Edgeworth cycles. No. 252. DICE Discussion Paper, 2017. https://www.econstor.eu/bitstream/10419/161673/ 1/889241651.pdf

Verlinda JA (2008) Do rockets rise faster and feathers fall slower in an atmosphere of local market power? Evidence from the retail gasoline market. J Ind Econ 56(3):581-612

Wang Z (2009a) Station level gasoline demand in an Australian market with regular price cycles. Aust J AgricResour Econ 53(4):467-483

Wang Z (2009b) (Mixed) strategy in oligopoly pricing: evidence from gasoline price cycles before and under a timing regulation. J Polit Econ 117(6):987-1030

Wills-Johnson N, Bloch H (2010) A simple spatial model for Edgeworth cycles. Econ Lett 108(3):334-336

Zimmerman PR, Yun JM, Taylor CT (2013) Edgeworth price cycles in gasoline: evidence from the United States. Rev Ind Organ 42(3):297-320

Publisher's Note Springer Nature remains neutral with regard to jurisdictional claims in published maps and institutional affiliations. 